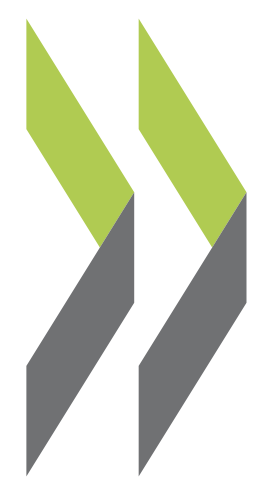

OECD Social, Employment and Migration Working Papers No. 93

\title{
The Welfare Effects of Social Mobility
}

\section{Justina A.V. Fischer}


Organisation de Coopération et de Développement Économiques

Organisation for Economic Co-operation and Development

16-Sep-2009

DIRECTORATE FOR EMPLOYMENT, LABOUR AND SOCIAL AFFAIRS

English text only

EMPLOYMENT, LABOUR AND SOCIAL AFFAIRS COMMITTEE

OECD SOCIAL, EMPLOYMENT AND MIGRATION WORKING PAPERS NO. 93

THE WELFARE EFFECTS OF SOCIAL MOBILITY

Justina A.V. Fischer

JEL Classification: 131, D31, D63, A14, J62

All Social, Employment and Migration Working Papers are now available through OECD's Internet website at http://www.oecd.org/els/workingpapers 


\title{
DIRECTORATE FOR EMPLOYMENT, LABOUR AND SOCIAL AFFAIRS
}

http://www.oecd.org/els

\section{OECD SOCIAL, EMPLOYMENT AND MIGRATION WORKING PAPERS}

\author{
http://www.oecd.org/els/workingpapers
}

This series is designed to make available to a wider readership selected labour market, social policy and migration studies prepared for use within the OECD. Authorship is usually collective, but principal writers are named. The papers are generally available only in their original language - English or French - with a summary in the other.

Comment on the series is welcome, and should be sent to the Directorate for Employment, Labour and Social Affairs, 2, rue André-Pascal, 75775 PARIS CEDEX 16, France.

The opinions expressed and arguments employed here are the responsibility of the author(s) and do not necessarily reflect those of the OECD. Applications for permission to reproduce or translate
all or part of this material should be made to:

\author{
Head of Publications Service \\ OECD \\ 2, rue André-Pascal \\ 75775 Paris, CEDEX 16 \\ France
}

Copyright OECD 2009 
DELSA/ELSA/WD/SEM(2009)21

\begin{abstract}
The question whether a socially mobile society is conducive to subjective well-being (SWB) has rarely been investigated. This paper fills this gap by analyzing the SWB effects of intergenerational earnings mobility and equality in education at the societal level. Using socio-demographic information on 44000 individuals in 30 OECD countries obtained from the World Values Survey, this study shows that living in a socially mobile society is conducive to individual life satisfaction. Differentiating between perceived and actual social mobility, we find that both exert rather independent effects, particularly in their interplay with income inequality. We identify a positive interaction of perceived social mobility that mitigates its overall SWB lowering effect, supporting Alesina et al. (2004). In contrast, a high degree of actual social mobility yields an overall impact of income inequality that is SWB lowering, while for low social mobility the effect of inequality is positive. These interactions hold stronger for pre-transfer than post-transfer income inequality. Actual social mobility appears to be appreciated only by conservative persons, while leftist oriented individuals are indifferent. Robustness is tested using a world sample.
\end{abstract}

\title{
RESUME
}

La question de savoir si une société socialement mobile est prédisposée au bien-être subjectif (SWB, d'après le sigle anglais) a rarement fait l'objet d'étude. Ce document vient combler ce manque en la matière en analysant les effets du SWB quant à la mobilité et l'égalité intergénérationnelle des gains dans l'éducation à un niveau sociétal. Cette étude s'est servie d'une information socio-démographique comptant 44000 individus dans 30 pays membres de l'OCDE tirée de l'enquête World Values Survey. Cette étude montre que le fait de vivre dans une société socialement mobile est propice à une satisfaction de vie individuelle. En séparant la mobilité sociale perçue à celle qui est réelle, nous observons que les deux exercent une influence plutôt indépendante, en particulier dans leur action mutuelle avec les inégalités de revenus. Une interaction positive de mobilité sociale perçue est identifiée, celle-ci limitant son influence globale du bien-être subjectif à la baisse, selon Alesina et al. (2004). A contrario, un fort degré de mobilité sociale réelle génère une influence générale sur l'inégalité des revenus qui diminue le SWB alors que pour une faible mobilité sociale les effets de l'inégalité sont positifs. Ces relations réciproques sont plus solides pour des inégalités de revenus avant transferts qu'après transferts. La mobilité sociale réelle semble être appréciée seulement par les conservateurs, alors que les individus orientés plus à gauche sont indifférents. La robustesse est aussi examinée en utilisant un échantillon mondial. 


\section{ACKNOWLEDGEMENTS}

The author thanks Andrew Clark, Henrik Jordahl, Alois Stutzer, and colleagues from the OECD such as Simon Chapple, Maria Huerta del Carmen, Enrico Giovannini, Mark Pearson, for helpful comments and suggestions. This paper was first written when the author was working as economist in the Social Policy Division (ELS) at the OECD, and builds on a previous version entitled "Social Mobility and Subjective Well-Being", ELS/SPD, February 2009, and a working party document of the ELS/SPD presented in October 2008. The views expressed in this paper are those of the authors alone, not necessarily of the OECD or any of its Member countries. This version: 20 July 2009.

+ Justina A.V. Fischer carried out this research while being employed as economist by ELS/SPD, OECD, 2008-2009; e-mail: JAVFischer@gmx.de 


\section{TABLE OF CONTENTS}

ABSTRACT
RESUME
ACKNOWLEDGEMENTS




\section{Tables}

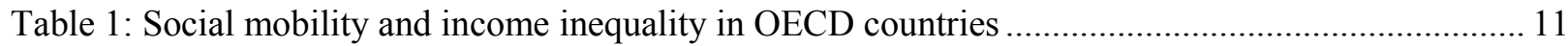

Table 2: Unconditional and conditional correlations of social mobility with SWB ….......................... 16

Table 3: Micro-level analysis of social mobility effects ..................................................................... 18

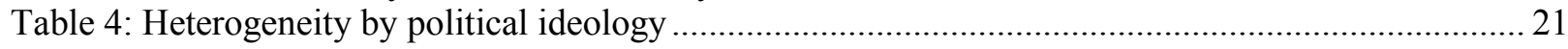

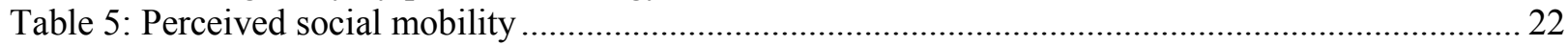

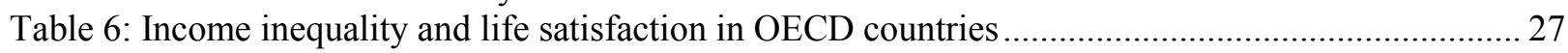

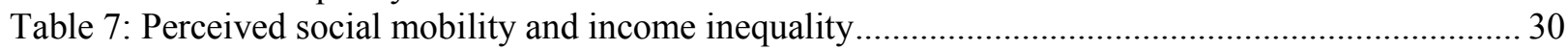

Table 8: Perceived, actual social mobility and income inequality ....................................................... 32

Table 9: Marginal effects of intergenerational income elasticity and market and final income

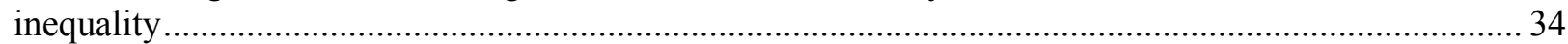

Table 10: Components of social mobility perceptions in OECD countries …........................................ 37

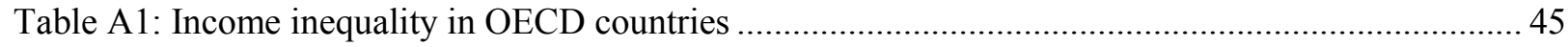

Table A2: Descriptive statistics of individual-specific factors............................................................... 46

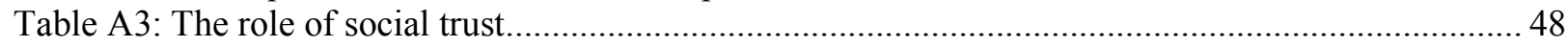

Table A4: Income inequality and life satisfaction in OECD countries: subsample ............................... 49

Table A5: Social mobility perceptions do not approximate actual social mobility .................................. 50

Table A6: Perceived social mobility: single components .................................................................. 51

Table A7: Perceived social mobility and income inequality: wage mobility subsample ......................... 52

Table A8: Correlations between income inequality and social mobility perceptions .............................53

Table A9: Correlations between income inequality and actual social mobility ....................................... 53

\section{Figures}

Graph 1: Correlation between social mobility in the labour market and SWB ..................................... 13

Graph 2a: Correlation between equal opportunities in education and SWB ......................................... 13

Graph 2b: Correlation between equal opportunities in education and SWB........................................ 14

Graph 3a: Consumption inequality of 2005 and Subjective Well-Being in OECD countries.................. 24

Graph 3b: Consumption inequality of 2000 and Subjective Well-Being in OECD countries .................... 24

Graph 3c: Market income inequality of 2005 and Subjective Well-Being in OECD countries................ 25

Graph 3d: Market income inequality of 2000 and Subjective Well-Being in OECD countries................ 25 
DELSA/ELSA/WD/SEM(2009)21

\section{Introduction}

\section{Topic of paper}

1. This paper addresses the question whether a socially mobile society is conducive to societal and individual welfare. In this paper we define social mobility as intergenerational improvement in income or social status, comparing the parental generation's standing with one's own (contrasting intra-generational changes that relate to the identical individual). ${ }^{1}$ Through aggregating individual social mobility to the population level we obtain a measure of the social mobility of society.

2. In this study, social mobility in society is captured by two direct measures: one that relates to average intergenerational earnings dependence in society, while the second assesses the average dependence of student's education attainment on their family background. In principle, both measures are not restricted to upwards mobility only, but available for OECD countries only. Notably, due to the crosssectional nature of the social mobility and happiness data employed, causality cannot be inferred from a methodological point of view, which leaves room for further explorations when international micro-macropanels become available.

3. Most of previous evidence of the welfare effects of social mobility in society, either actual or perceived, has been only indirect. Alesina, DiTella and MacCulloch (2004) use a perceived social mobility argument to explain the differential impacts of income inequality on individual subjective well-being (SWB) between the US and Western Europe. In particular, they relate the insignificant effect of income dispersion in the US to prospects of upward mobility, while linking the negative impact in Western Europe to social immobility. In a similar vein, Senik (2008) compares the effects of reference income, the income level on which social comparisons are based on, across Western and Eastern European countries. She explains the beneficial, SWB increasing effects in the post-communist countries with a rising-incometrajectory argument. Potentially, the positive, beneficial reference income effects at the neighbourhood level, with simultaneously negative, SWB-decreasing comparison income effects at the national level, reported in Kingdon and Knight (2007), may equally be explained by differences in (perceived) social mobility: while neighbours' income level may play a role model for their own (upward) income expectations, the national reference income may merely yield negative social comparisons effects. Social mobility effects at the individual level are assessed by Clark and D'Angelo (2008). Comparing the type of job held by parents with that occupied by their child, the impact of a personal intergenerational improvement on individual SWB is clearly positive. Taken all together, these studies provide only indirect evidence, sometimes only conjectures, on the effects of living in a socially mobile society on well-being. Indeed, direct empirical evidence on the subjective well-being effects of social mobility, and the nature of the society an individual lives in, is still lacking.

\section{Outline of paper}

4. The rest of the paper is organized as follows: section 2 introduces the data and provides descriptive statistics, while the subsequent section briefly discusses the estimation techniques. Section 4 analyzes the SWB models and discusses the results for actual and perceived social mobility, also taking

1. As the concept of social mobility implies contrasting individual social status with social status of the preceding generation, it is somewhat related to the field of 'social comparisons' or 'relative deprivation', which assumes a comparison of individual's income with a certain contemporaneous threshold income, e.g. average income. For a literature overview, see, e.g., Clark and Oswald (1996), Ferrer-I-Carbonell (2005), Fischer and Torgler (2008). For a thorough empirical assessment of relative and absolute income effects on happiness, see Ferrer-I-Carbonell (2005). 
account of heterogeneity by respondent's political ideology. Finally, the models test the interplays of perceived and social mobility with pre- and post-transfer income inequality, in the tradition of Alesina et al. (2004). Section 5 provides further, more speculative explanations of the empirical findings, while section 6 concludes.

\section{Data}

\section{Micro data on $S W B$}

5. Using the World Values Survey (WVS) data from 1997 to 2001 for the subsample of 30 OECD countries, we extract information on 44'000 persons. Subjective Well-Being is measured using the life satisfaction question, which asks, "All things considered, how satisfied are you with your life as whole these days ?", and rates its answers on a 10-point scale, ranging from "completely dissatisfied" to "completely satisfied". These data have been previously employed in numerous scientific articles written by economists, sociologists and political scientists, and focuses on the cognitive, evaluative component of subjective well-being in a broader sense (e.g., Bjørnskov, Dreher and Fischer, 2008a, b; Helliwell and Huang, 2007). For the country-level analyses, the population share of those responding in the highest three categories is employed (following e.g. Bjørnskov, Dreher, and Fischer, 2007), while the micro-level analysis exploits the full scale of the life satisfaction question.

\section{Social mobility measures: intergenerational earnings elasticity and mobility in educational attainment}

6. This paper addresses the question whether living in a society with more social mobility is conducive to SWB. In this paper we define social mobility as intergenerational improvement in income or social status, comparing the parental generation's standing with one's own (contrasting intragenerational changes that relate to the identical individual). Thus, in a society with equal opportunities we should observe wages and earnings which are less dependent on family background and parental income (Roemer, 2002). Already at school, student performance should be less determined by parental education level.

7. To measure the degree of social mobility in society, two measures are employed: first, the intergenerational earnings elasticity, which measures the dependence of one's own life-time income to parental income, based on a father-son comparison. ${ }^{2}$ The earnings elasticity in this study is obtained from estimating a model in which son's log earnings is a function of log of father's earnings, usually also correcting for life-cycle bias, based on the theoretical framework developed by Becker and Tomes (1979). The estimated coefficient represents then intergenerational earnings elasticity. In all OECD countries, this coefficient takes on positive values ranging from 0.15 to 0.5 which reflect smaller and larger intergenerational persistence, on average. The extreme value of 0 indicates complete generational mobility, with no relation between parent and child outcomes, while the maximum value of 1 reflects complete immobility. A value of 0.5 implies that $50 \%$ of father's earnings advantage is passed on to his son. According to Corak (2006), even small values can indicate substantial earnings differences by parental background: e.g. for the US, an elasticity of 0.4 implies that adult children of high-income parents earn more than two-and-a-half higher incomes compared to descendents of low-income parents (in case of 0.2 , the income advantage is still 1.64). This earnings elasticity measure is, however, only available for 12

2. Ideally, elasticity would be based on both parents' income and their female and male childrens' incomes, with elasticity measuring "the fraction of income differences between two parents that, on average, is observed among their children in adulthood" (Corak, 2006). However, due to low female labour force participation rates in the parental generation, longitudinal data on female parental incomes is still largely missing, so any estimated intergenerational wage elasticity would be unreliable. 
countries in our sample. The data are obtained from OECD (2008), which summarizes the meta-studies by D'Addio (2007) and Corak (2006), which present elasticities corrected for various biases (e.g. measurement errors due to natural income fluctuations) and made cross-nationally comparable. To ease interpretation of the empirical findings, elasticity estimates have been multiplied with -1 so that higher values indicate more social mobility in the labour market. In our sample, the least mobile countries are the United Kingdom (-0.5), Italy (-0.48), and the USA (-0.47); the most socially mobile OECD countries in our sample are Denmark (-0.15) and Norway (-0.17) (see Table 1).

8. The second measure assesses social mobility in society before the labour market entry takes place, namely at the education stage. Intergenerational transmission of education is often captured by a measure of dependency of student's educational attainment of her parents' education. Available for this study are mobility measures based on PISA 2003 student performance data in Mathematics and the information on family background. More precisely, educational mobility is approximated by the difference between the mean student test score in the high-education-family-background-subsample and that in the medium-level-of-parental-education-subsample. This difference in means is calculated for mother's and father's education background separately (but does not differentiate by student's gender). To ensure crossnational comparability, levels of parental education are measured on the international, standardized ISCED scale, with level 3 (upper secondary education) representing the medium level of education and levels 5 or 6 (completed tertiary education) reflecting the highest level in this comparison. For example, in Spain, the mean test score of students with mothers who have a completed tertiary education is 514 points, while that for students whose mothers have an upper secondary education, the medium level of parental education, is 489. Thus, a higher-education background (compared to a medium level of education-background) yields an average advantage of $514-489=25$ test score points (see Table 1), a quarter of a standard deviation of the PISA test scores. ${ }^{3}$ These differences are calculated for 29 OECD countries based on the PISA 2003 scores in Mathematics, obtained from OECD (2004) and OECD (2007).

9. To ease interpretation of this mobility measure, its values have been multiplied by -1 so that higher values reflect more mobility in terms of intergenerational dependency of educational attainment. With respect to maternal education level (and excluding Mexico as outlying observation) ${ }^{4}$, this recoded measure ranges between -57.74 and 2.41 PISA test score points, with negative values indicating educational immobility, as the educational advantage persists over generations. Values close to zero imply that, on average, both student subsamples by parental education perform equally well, indicating that family background plays no role for student attainment. ${ }^{5}$ Table 1 shows that highly immobile countries (in terms of maternal education level) are all Eastern European OECD countries (Poland: -53.94 points, Czech Republic: -54.27 points, Hungary: -57.74 points and the Slovak Republic: -48.59 points), while most mobile are Italy (-1.28 points), Portugal (-1.7 points), Sweden (-2.59 points), and Switzerland (2.41 points).

\section{Perceived social mobility}

10. In the course of this analysis, an approximate measure of perceived social mobility is employed, constructed using three questions of the WVS. The questions account for confidence in one's country's education system, the belief that it is possible to escape from poverty, and that poverty is caused by

3. The standardized international mean is 500 test score points with a standard deviation of 100 points.

4. The value of 20.14 points for Mexico indicates some considerable downward mobility in terms of educational attainment for those with an educationally advantageous family background.

5. Alternatively, education mobility in terms of years of education could have been employed. However, the duration may just reflect the efficiency of the schooling or education system. In addition, it is not outcomefocused. 
laziness and lack of will, as opposed to bad luck. The latter two WVS questions have been used by Alesina, Glaeser and Sacerdote (2001) to motivate the differences in perceived social mobility between the US and Western Europe. A person is defined as perceiving her society as socially mobile if she responds positively to at least one of three questions. Altogether, this procedure yields a social mobility perception measure for $30^{\prime} 000$ individuals in 25 OECD countries, with the confidence in education measure clearly dominating. ${ }^{6}$ Thus, this measure builds largely on the idea that education is an important determinant of socio-economic position, and that equal opportunities in education generate socio-economic mobility, which is empirically supported for developed countries by the meta-study of Corak (2006). However, one may argue that intergenerational mobility in education does not reflect overall social mobility, be it actual or perceived. For reasons of robustness, a more narrow definition of perceived social mobility is employed, which is based only on the latter two components, but available for fewer countries and individuals. All mobility and national income measures are taken from the OECD databases and the publication 'Society at a Glance, 2006' (OECD, 2007).

\section{Other control variables at the country level}

11. In various robustness tests, we employ the Net National Income per capita (NNI, in its log form), which approximates the level of disposable income in the population, and social trust in the population. ${ }^{7}$ Social trust at the societal level is measured as the population share of yes-respondents to the World Values Survey question "Generally speaking, would you say that most people can be trusted or that you need be very careful in dealing with people?". Table 1 lists the values of the actual social mobility (three measures), the perceived social mobility (population mean), the corresponding GINI coefficients, and subjective well-being (population share of happiest) for 30 OECD countries.

\section{Methodology}

12. Correlation analyses have been carried out at the country level, with individual-level information aggregated to the societal level, giving rise to 30 data points. A first robustness test with respect to national income and social capital is carried out, both applying OLS and robust regressions (RR) that take account of potential outliers in the sample. ${ }^{8}$

13. The second and core part of this paper applies multi-level multivariate regressions exploiting the micro-level as well as country-level variation in the data. Combining individual-level information with country characteristics, we obtain a cross-section to which we apply weighted OLS, with clustering by countries to take account of within-group correlations. In particular, this technique corrects for the fact that social mobility as measured (as well as GDP) varies only across countries, so that the standard errors of the estimates are correctly calculated.

6. The confidence in education measure is available for 21 countries, the remaining two measures for three countries (AUS, NOR, NZL).

7. NNI is defined as GDP plus wages, earnings, salaries and property income earned abroad, minus the depreciation of fixed capital assets. NNI is a more accurate measure of economic well-being of the population compared to GDP.

8. In a robust regression, first, any observation is excluded that has a Cook's D value of greater than 1, and second, based on the absolute size of previous-round residuals, observations are assigned weights from 0 to 1 . 
Table 1: Social mobility and income inequality in OECD countries

\begin{tabular}{|c|c|c|c|c|c|c|c|}
\hline Country & $\begin{array}{c}\text { Market } \\
\text { Gini } 2005 \\
\end{array}$ & Final Gini 2005 & $\begin{array}{l}\text { Maternal } \\
\text { education- } \\
\text { dependence } \\
\text { of student } \\
\text { performance }\end{array}$ & $\begin{array}{l}\text { Paternal } \\
\text { education- } \\
\text { dependence } \\
\text { of student } \\
\text { performance }\end{array}$ & $\begin{array}{l}\text { Intergenera- } \\
\text { tional earnings } \\
\text { elasticity }\end{array}$ & $\begin{array}{c}\text { Perceived } \\
\text { social mobility } \\
\text { (population } \\
\text { share) }\end{array}$ & SWB \\
\hline Australia & 30 & 46 & -28.88 & -35.44 & -0.162 & 69.9 & 60.84 \\
\hline Austria & 27 & 43 & -11.69 & -6.6 & & 86.5 & 69.13 \\
\hline Belgium & 27 & 49 & -31.7 & -28.29 & & 78.2 & 62.46 \\
\hline Canada & 32 & 44 & -21.03 & -23.05 & -0.19 & & 66.60 \\
\hline $\begin{array}{l}\text { Czech } \\
\text { Republic }\end{array}$ & 28 & 35 & -54.27 & -61.98 & & 55.7 & 47.42 \\
\hline Denmark & 27 & 47 & -24.94 & -40.95 & -0.15 & 75.1 & 76.75 \\
\hline Finland & 30 & 51 & -16.97 & -21.09 & -0.18 & 88.9 & 72.68 \\
\hline France & 23 & 42 & -16.5 & -19.02 & -0.41 & 69.3 & 44.27 \\
\hline Germany & 32 & & -21.28 & -29.72 & -0.32 & 73.8 & 61.63 \\
\hline Greece & 27 & 39 & -20.6 & -15.9 & & 29.0 & 41.57 \\
\hline Hungary & 28 & 48 & -57.74 & -63.91 & & 63.2 & 26.27 \\
\hline Iceland & 34 & 46 & -22 & -20.05 & & 82.3 & 74.43 \\
\hline Ireland & 32 & & -19.18 & -23.84 & & 87.8 & 69.74 \\
\hline Italy & 29 & & -1.28 & 3.26 & -0.48 & 53.2 & 49.24 \\
\hline Japan & 33 & 42 & -28.49 & -33.87 & & & 36.47 \\
\hline Korea & 28 & 37 & -20.31 & -30.77 & & & 31.20 \\
\hline Luxembourg & 35 & 56 & -25.49 & -23.59 & & 68.1 & 65.75 \\
\hline Mexico & 32 & 44 & 20.14 & 11.07 & & & 71.67 \\
\hline Netherlands & 31 & 34 & -32.6 & -28.56 & & 71.9 & 69.48 \\
\hline New Zealand & 26 & 45 & -13.26 & -32.25 & & 64.4 & 63.57 \\
\hline Norway & 47 & & -27.37 & -23.16 & -0.17 & 80.7 & 63.93 \\
\hline Poland & 27 & 42 & -53.94 & -55.1 & & 80.9 & 38.79 \\
\hline Portugal & 28 & 43 & -1.7 & 11.26 & & 61.5 & 41.04 \\
\hline $\begin{array}{l}\text { Slovak } \\
\text { Republic }\end{array}$ & 34 & 47 & -48.59 & -62.22 & & 76.6 & 30.05 \\
\hline Spain & 37 & 57 & -25.07 & -27.14 & -0.32 & 67.8 & 42.80 \\
\hline Sweden & 38 & 54 & -2.59 & -2.48 & -0.27 & 67.1 & 62.96 \\
\hline Switzerland & 27 & 46 & 2.41 & -8.71 & & & 75.12 \\
\hline Turkey & 23 & 43 & -34.85 & -50.23 & & 57.4 & 28.52 \\
\hline $\begin{array}{l}\text { United } \\
\text { Kingdom }\end{array}$ & 43 & & & & -0.5 & 65.1 & 57.08 \\
\hline United States & 38 & 46 & -28.86 & -34.53 & -0.47 & & 46.92 \\
\hline
\end{tabular}

Notes: Perceived social mobility is the percentage of population believing that their society allows social mobility, based on the WVS 1997-2001. Market and Final Gini are obtained from OECD(2008), while actual social mobility is taken from OECD (2007). SWB is a measure of societal well-being, based on the WVS 1997-2001, expressed as percentage of population expressing the three highest scores out of ten life satisfaction scores. 
14. The application of OLS to a categorical dependent life satisfaction variable can be justified based on Ferrer-I-Carbonell and Frijters (2004). They show that using OLS in place of ordered probit in SWB analyses preserves the direction of the effects, the significance levels of the coefficient estimates as well as their relative importance. Using OLS has also the advantage that coefficients can directly be interpreted as marginal effects, and that interaction terms are meaningful, so that total (marginal) effects can easily be calculated. Coefficients in OLS regressions relate to changes in categories of life satisfaction. ${ }^{9}$

\section{Results}

\section{Simple correlations between happiness in population and social mobility}

15. We start with investigating simple correlations between SWB in the population and social mobility. Actual social mobility is measured either by the (recoded) elasticity of one's own wage to parental income or is proxied by the (recoded) deviation of student performance in PISA 2003 with a higheducation family background from the medium-education performance, so that higher values correspond with more social mobility. As the following Graphs 1 and 2 suggest, actual social mobility show the expected positive correlations with Subjective Well-Being in OECD countries. The correlation coefficients are $\rho=0.75,0.49$, and 0.45 , respectively, indicating that stronger intergenerational dependence of economic success lowers societal well-being. ${ }^{10}$

9. In contrast, marginal effects calculated based on ordered probit estimates relate to changes in probability of reporting a certain (pre-determined) SWB category.

10. Referring to the introduction of this paper, equal opportunities may also be approximated by more economic freedom and civil participation possibilities, e.g. measured by the Gastil index of civil liberties (www.freedomhouse.org). Also for this measures of social mobility we find strong positive correlations with SWB at the country level, $\rho=0.64$. On the other hand, social mobility may also be linked to government interventions that correct 'unfair' market outcomes. For OECD countries, we find a strong positive relation between confidence in the social security system and SWB $(\rho=0.46)$. Indeed the importance of fairness perceptions for SWB has been analyzed in e.g. Tortia (2008). 
Graph 1: Correlation between social mobility in the labour market and SWB

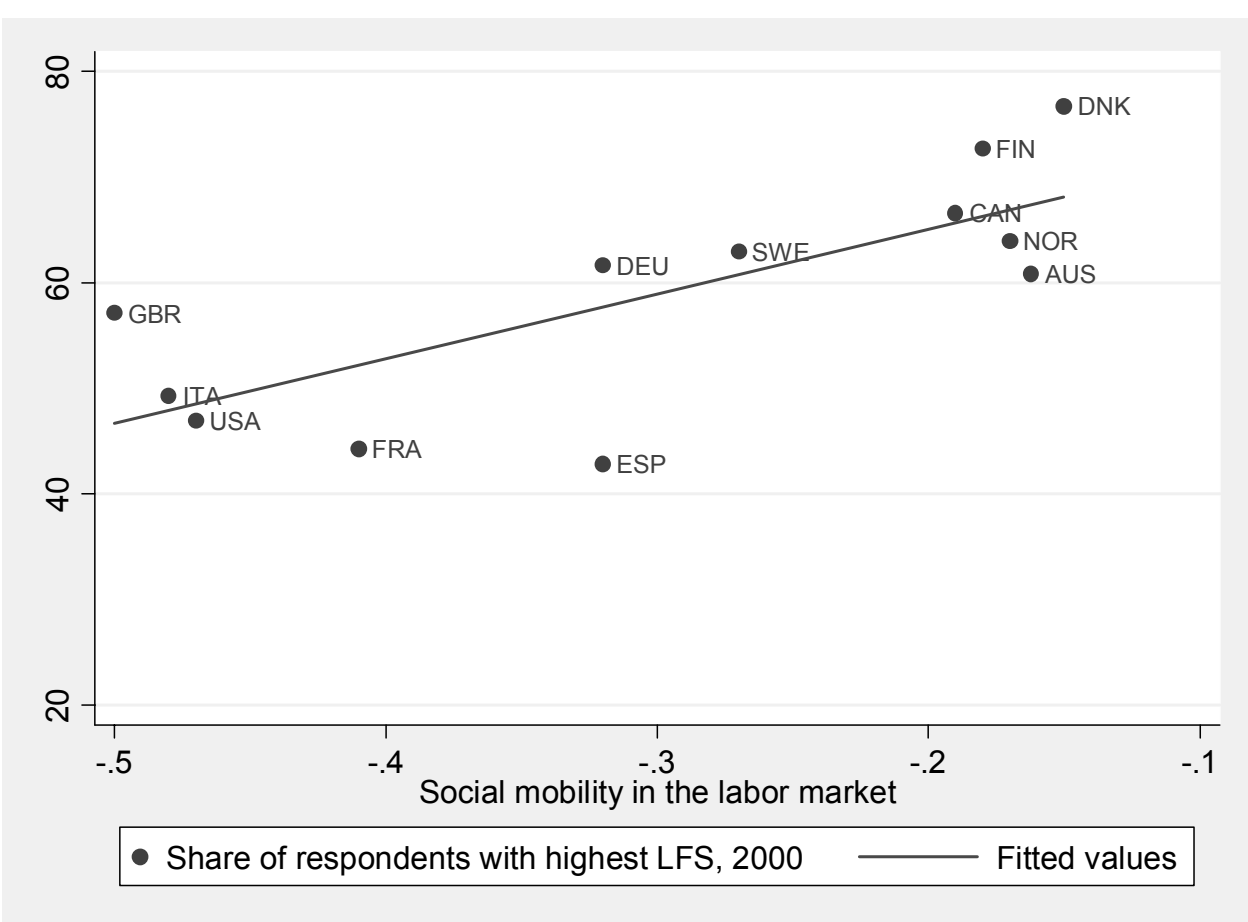

Graph 2a: Correlation between equal opportunities in education and SWB

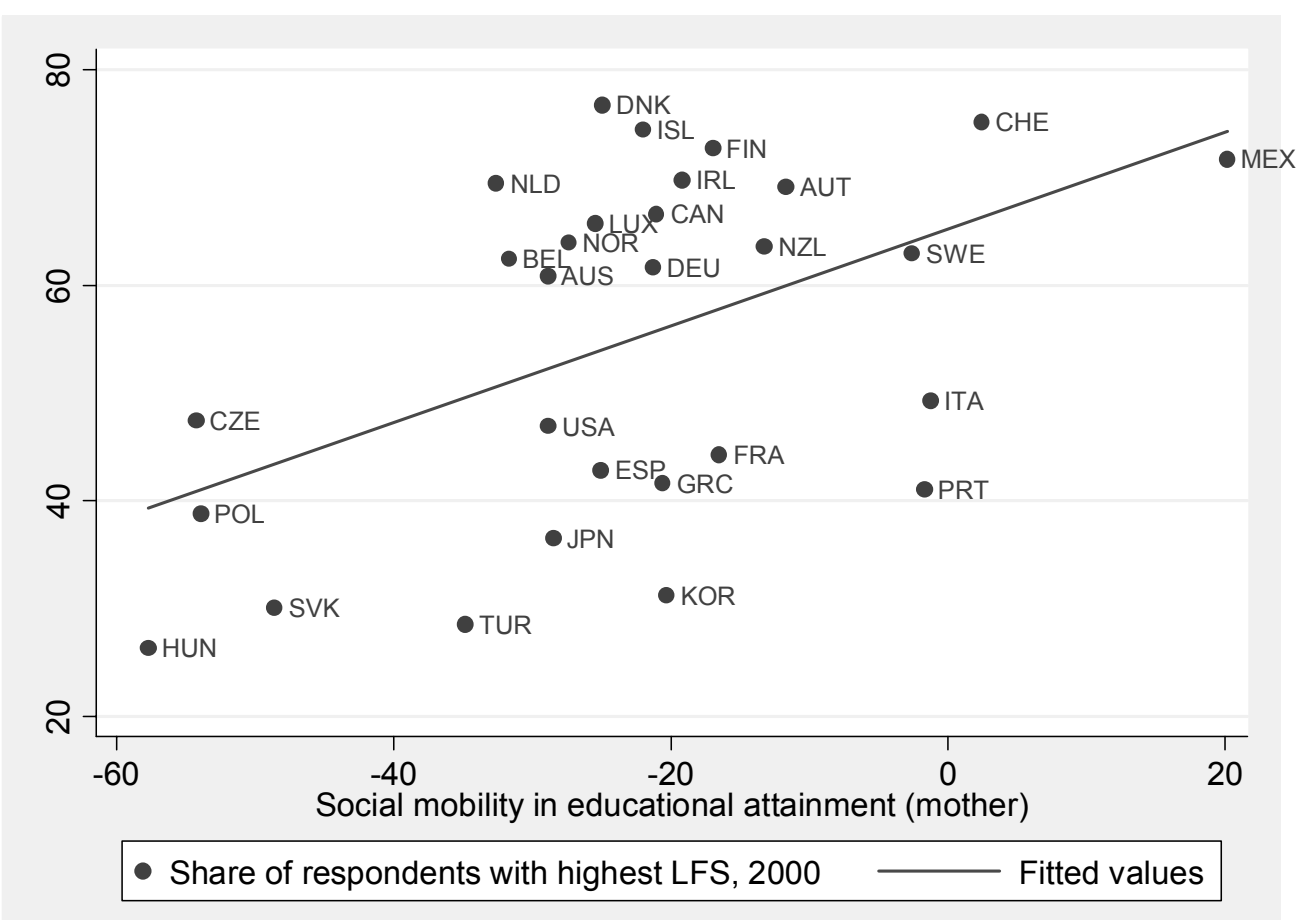


Graph 2b: Correlation between equal opportunities in education and SWB

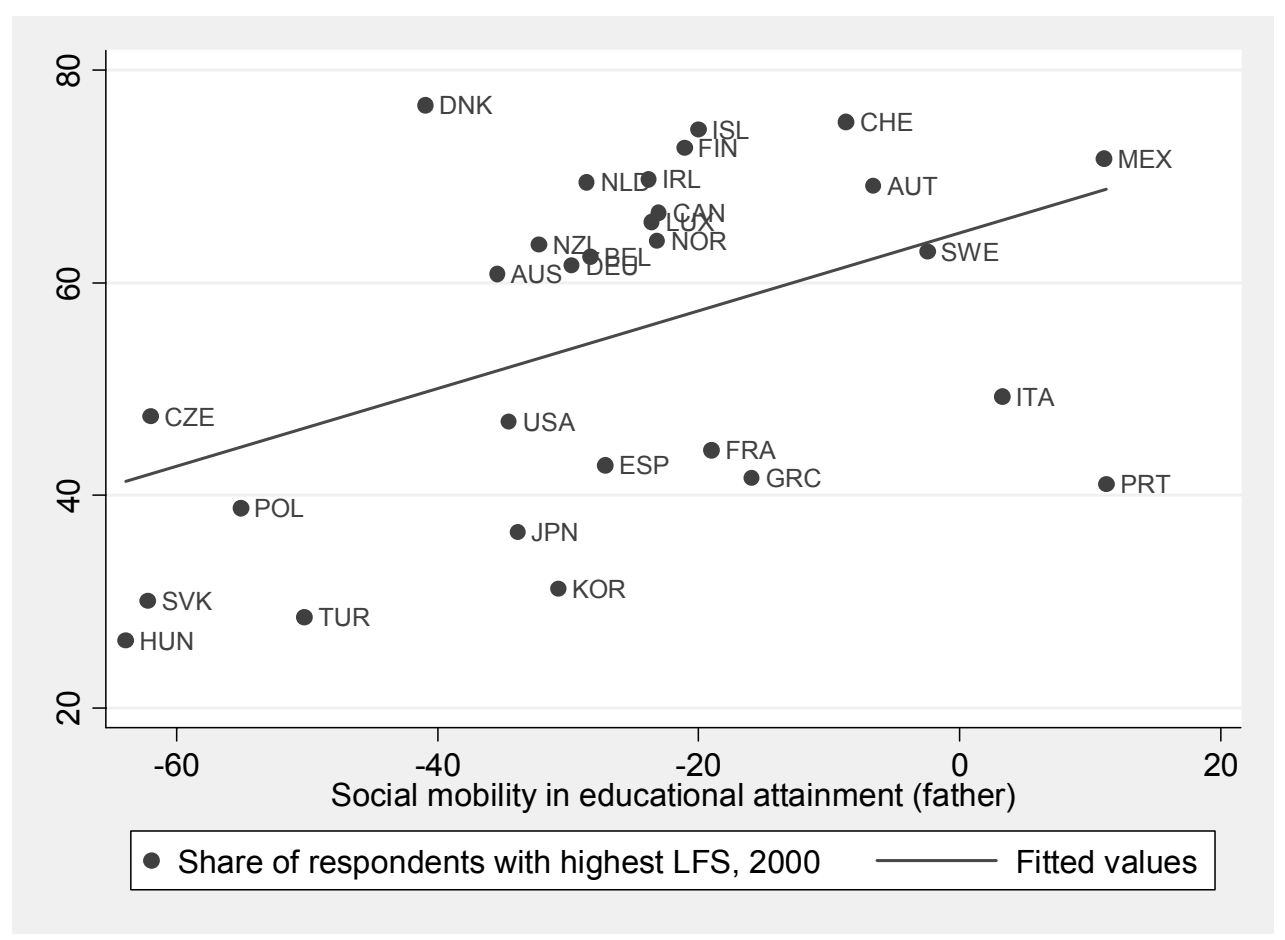

\section{Testing for alternative explanations: national wealth and trust}

16. It may be argued that the positive correlations between social mobility and SWB are driven by unobserved factors: national wealth, or, alternatively, social trust. Countries that are socially more mobile should allocate human capital more efficiently, and, in the long-run, grow faster and reach higher levels of national wealth. ${ }^{11}$ This parallel development is reflected in the so-called modernization hypothesis of societal progress. On the other hand, social trust may well be a pre-condition for a socially mobile society. Social trust is the general belief that one treats each other in a fair, non-abusive manner (Jordahl, 2007; Bjørnskov, 2007). As social mobility implies unpredictable shifts of bargaining power across groups and individuals, a trusting and trustworthy environment may protect the individual against the adverse effects of social mobility. ${ }^{12}$ Uslaner (2008) suggests that social trust is a rather time-invariant feature of society,

11. For example, in Western Europe, (proto-)industrialization was made possible through the deliberate destruction of the medieval feudal system (manoralism), allowing for geographical mobility and land reform, introduction of economic freedom, and destruction of the craft gild system (England: 1660/ 1760, France: 1789-1793, Prussia: 1807/1810/1866), allowing for entrepreneurship, price competition between manufactures, technological progress, and performance-based pay schemes. A similar linkage between industrialization and social mobility can be observed in Russia under Tzar Peter I (the Great, 1682 - 1725), whose reforms included not only state support for foundation of private enterprises, but also modernization of government administration and state control of the church. Another example is Japan in 1854, the year the harbours were re-opened to foreign goods and knowledge after centuries of isolation, accompanied by the deliberate abolition of the Japanese (semi-)feudal system in 1871/1877 under emperor Mutsuhito (1867 - 1912).

12. That other-regarding fairness considerations put a constraint on purely self-regarding behaviour has been shown in experimental economics, e.g. in so-called one-shot dictator distribution games in which nonsharing cannot not be punished by the receiver (Fehr and Schmidt, 1999). Bergren and Jordahl (2008) claim that economic freedom in society lets social trust emerge; in this line, social mobility would trigger social trust, equally giving rise to their positive correlation. 
transmitted through the family line. Thus, social mobility may just approximate national wealth or social trust, but not exert an impact of its own.

17. The correlations between NNI per capita (as of 2000) and the social mobility measures are as expected for mobility in education $(\rho=0.25 ; \rho=0.37)$ (but not for intergenerational wage mobility, $\rho=$ $0.03)$, while the correlation of NNI with SWB is positive and significant $(\rho=0.59) .{ }^{13}$ Thus, living in a rich country goes along with having more equal educational opportunities. National wealth may also be associated with, and thus approximate, the quality of government institutions. The correlations of $\log (\mathrm{NNI})$ with measures of government effectiveness (Kaufman et al., 2008), the rule of law (Fraser Institute), and the absence of perceived corruption (Transparency International) exceed $\rho=0.66 .{ }^{14}$ The positive correlation coefficients between these institutional quality measures and the social mobility indicators reveal that better institutions are found in more socially mobile societies, which exceed 0.5 for intergenerational wage mobility. For the educational mobility measures, the correlations show the same tendency, but are smaller in size. ${ }^{15}$

\section{Partial correlations between inequality and SWB in the population using OLS and RR}

18. To account for this correlation structure, multivariate regressions using OLS and Robust Regression Analysis (RR) for 30 OECD countries are carried out, with country's SWB as dependent variable, and as explanatory factors the $\log$ of NNI, social trust, and our mobility measure of interest. ${ }^{16}$ Table 2 reports the results for national income, while Table A3 of the Appendix adds social trust in society.

19. In Table 2, we also report the coefficient estimates for the unconditional association between social mobility and national happiness, applying the same weights. The similarity of the conditional with the unconditional social mobility coefficients (mostly staying significant) suggests that unobserved national wealth does not drive our previous results. Obviously, providing social mobility that may reflect equal opportunities, which is beneficial to SWB, is not a question of a country's financial resources. According to Table 2, an increase in social mobility in terms of intergenerational wage elasticity by 0.1 increases the share of happiest persons in society by 6 percentage points. Similarly, an increase in educational attainment independence by 10 test score points equally increases the happy population share by 6.6 percentage points. The regressions for social trust yield the coefficients for mobility in education unchanged. In contrast, the coefficient on social mobility in terms of intergenerational earnings elasticity, which is only available for 12 countries, appears reduced in size, but stays jointly significant. Thus, the SWB effects of mobility in the labour market are partly mediated by social trust, which is not the case for educational mobility. Possibly, actual earnings are more decisive determinants of one's socio-economic positions in society than is education. Nevertheless, both mobility measures stay influential.

20. Taken altogether, the social mobility effects for SWB do not appear to account for unobserved country characteristics such as social trust and national income.

13. The correlation with NNI (2000) with intergenerational earnings elasticity is $\rho=0.03$, with maternal and paternal education-dependence of student performance $\rho=0.25$ and $\rho=0.37$, respectively.

14. The correlation coefficients are $\rho=0.86,0.66$, and 0.73 , respectively.

15. Correlations coefficients with recoded wage elasticity are $\rho=0.5,0.68$, and 0.72 , respectively, and with recoded dependency on mothers (father's) educational background $\rho=0.2(0.26), 0.08(0.12)$, and $\rho=0.25$ (0.26), respectively.

16. Adding NNI to models 3 to 6 increases the adjusted R2 from roughly 0.2 to above 0.4 , indicating a considerably better model fit. 
Table 2: Unconditional and conditional correlations of social mobility with SWB

\begin{tabular}{|l|c|c|c|c|c|c|}
\hline & 1 & 2 & 3 & 4 & 5 & 6 \\
\hline & OLS & RR & OLS & RR & OLS & RR \\
\hline Social Mobility measure-only model & & & & & & \\
\hline (same weights) & $61.170^{* *}$ & $61.407^{* *}$ & $0.449^{* *}$ & $0.464^{* *}$ & $0.366^{*}$ & $0.397^{* *}$ \\
\hline Labour market mobility & {$[3.83]$} & {$[4.05]$} & {$[3.74]$} & {$[3.95]$} & {$[2.51]$} & {$[2.89]$} \\
\hline & & & & & & \\
\hline Educational mobility (mother) & $60.905^{* *}$ & $61.266^{* *}$ & & & & \\
\hline & {$[3.44]$} & {$[3.70]$} & & & & \\
\hline Educational mobility (father) & & & $0.330^{*}$ & $0.340^{*}$ & & \\
\hline & & & {$[2.52]$} & {$[2.73]$} & & \\
\hline Log (NNI) & & & & & 0.218 & 0.231 \\
\hline & & & & & {$[1.37]$} & {$[1.54]$} \\
\hline Constant & 8.609 & 5.972 & $13.408^{* *}$ & $13.240^{* *}$ & $13.160^{* *}$ & $12.994^{* *}$ \\
\hline & {$[0.48]$} & {$[0.36]$} & {$[4.03]$} & {$[4.28]$} & {$[2.99]$} & {$[3.21]$} \\
\hline Observations & -9.437 & 17.318 & $-68.652+$ & $-66.445^{*}$ & -67.988 & -65.679 \\
\hline Adjusted R-squared & {$[0.05]$} & {$[0.10]$} & {$[1.99]$} & {$[2.07]$} & {$[1.46]$} & {$[1.53]$} \\
\hline Adjusted R-squared (simple model) & 12 & 12 & 29 & 29 & 29 & 29 \\
\hline Nit) Den & 0.4800 & 0.4996 & 0.4271 & 0.4543 & 0.3669 & 0.4093 \\
\hline
\end{tabular}

Notes: Dependent variable: Subjective Well-Being measured at the country level as population share of respondents in the three highest life satisfaction categories out of 10. 'Labour market mobility' is derived from intergenerational earnings elasticity, while 'educational mobility (mother/father)' is measured in terms of maternal/paternal education-dependence. Higher values indicate more social mobility. Regressions for a sample of 30 OECD countries. '**', '“', ' + ' denote significances at the 1, 5 and 10 percent levels, respectively. T-statistics are reported in brackets. 'OLS' denotes Ordinary Least Squares with robust Huber/White/Sandwich standard errors, while 'RR' denotes OLS with weights applied from a previously run Robust Regression.

\subsection{Main specification: Societal versus individual social mobility}

21. Analogous analyses of the individual SWB effects of living in mobile society using a combined micro-macro-level approach are carried out, in which individual-level characteristics are combined with country-specific factors (e.g. Bjørnskov, Dreher and Fischer (2008a, b). This approach exploits the variation in subjective well-being across individuals, while the variation of factors at the country level remains the same. The full model includes controls for gender, age, marital status, education, income, denomination, political ideology and various facets of social capital, alongside with national income. As described in the methodology section, OLS with observations clustered at the country level is applied to account for within-group correlation. Table A2 provides descriptive statistics of the individual-level determinants.

\section{SWB effects of social mobility}

22. Table 3 shows that social mobility in society exerts a well-being raising influence, as does national income. In the full models (columns 1 and 3), the marginal effects of intergenerational labour market mobility and mobility in educational attainment are 1.33 and $0.012-0.017$, respectively, indicating the happiness gain from a one-unit increase in the explanatory variable. Consequently, moving from a completely immobile (-1) to a completely mobile society (0) in terms of earnings would, ceteris paribus and causally interpreted, increase an individual's well-being by more than one satisfaction category (1.33), on average. More feasible in reality is a move from the (recoded) maximum wage persistence in our OECD sample (-0.5, e.g. UK) to maximum mobility ( -0.15 , Denmark), that would yield a happiness gain by half of a SWB category. For educational mobility, a decrease of parental background advantage by 50 test score points (maximum in sample: -57 points) would increase life satisfaction by more than $2 / 3$ of a category, on 
average. Assessment of the relative importance of social mobility effects is achieved through comparison with the marginal effects for the control variables in a baseline model reported in Table A2 of the Appendix. The SWB effects of about $2 / 3$ of a category or more triggered by considerable changes in social mobility are only comparable to associations of SWB (in absolute terms) with being in a medium-to-high income category compared to being in the lowest income category (yielding happiness gains of about $70 \%$ to $99 \%$ of a category), or being unemployed (-80\% of a category). SWB effects of half of a category are still quite sizable and are similar in size to e.g., having a medium-level income (compared to the lowest income), or being married. ${ }^{17}$ Comparably large impacts are also observable for the log of national income, as Table 3 suggests $(60 \%-100 \%$ of a SWB category, depending on the model specification).

\section{The relation between socio-demographic characteristics and mobility in society}

23. Stronger results for earnings mobility are observable when only gender and age, the only truly exogenous individual-specific determinants, are employed (columns 2, 4, and 6 of Table 3). Compared to the full model 1, which employs all individual-level controls, the coefficient size of intergenerational earnings elasticity appears larger in absolute terms (1.33 vs. 1.69, representing an increase by $30 \%$ ), suggesting that parts of its effects are captured by choice-driven individual-specific characteristics as education and income. In this light, the significant effect of social mobility in the full model is particularly noteworthy, suggesting that social mobility at the societal level and social mobility experienced as past personal history are distinct.

24. This observation of differential marginal effects across model specifications is not made for social mobility in educational attainment, for which almost all coefficients remain unaffected by the inclusion of potentially endogenous micro-level control variables (e.g. column 3 versus column 4). This similarity in coefficients on intergenerational education dependency across model variants remains in the smaller sample for the intergenerational wage elasticity variable.

\section{The relation between mobility in the labour market and in education}

25. In Table 3, labour market mobility in society has a different effect on SWB according to whether individual income is excluded or included in the model. In contrast, for mobility in educational attainment no such observation is made: the coefficient estimate on education mobility is insensitive to the inclusion of respondent's education, income, and occupational status. A possible explanation is that equality in educational opportunity does not fully transmit into equality of opportunities in the labour market.

26. Breen (2004) suggests that in countries with a policy of providing equal educational opportunities soft skills that are not learned at school but in the family may well gain in importance for obtaining certain occupational positions and for career opportunities. Indeed, the correlation coefficients between labour market mobility and education mobility are low and sensitive to the number of countries included in the sample: the small negative correlation in the full sample $(\rho=-0.4)$ disappears when Italy is excluded, yielding no correlation $(\rho=-0.08) .{ }^{18}$ This is in accordance with the estimates of Table 3 that suggest that there is no direct causal chain from educational mobility to income and occupation.

17. As Table A2 of the Appendix shows, sizes of most of the significant OLS coefficient estimates on determinants of SWB in 30 OECD countries do not exceed the value of 0.35 in absolute terms.

18. The positive correlation in Corak (2006) is based on a much smaller sample and partly less precise measures. 
DELSA/ELSA/WD/SEM(2009)21

Table 3: Micro-level analysis of social mobility effects

\begin{tabular}{|c|c|c|c|c|c|c|}
\hline & 1 & 2 & 3 & 4 & 5 & 6 \\
\hline \multirow[t]{2}{*}{ Labour market mobility } & $1.333^{* *}$ & $1.696^{*}$ & & & & \\
\hline & {$[4.00]$} & [3.01] & & & & \\
\hline \multirow[t]{2}{*}{ Educational mobility (mother) } & & & $0.014^{*}$ & $0.017^{* *}$ & & \\
\hline & & & {$[2.48]$} & {$[2.84]$} & & \\
\hline \multirow[t]{2}{*}{ Educational mobility (father) } & & & & & $0.013+$ & $0.012+$ \\
\hline & & & & & [2.04] & [1.75] \\
\hline \multirow[t]{2}{*}{$\log (\mathrm{NNI})$} & $1.059^{* *}$ & 0.929 & $0.662^{* *}$ & $0.766^{* *}$ & $0.596^{*}$ & $0.746^{* *}$ \\
\hline & {$[6.23]$} & [1.75] & {$[3.59]$} & {$[6.10]$} & {$[2.70]$} & {$[4.24]$} \\
\hline \multirow[t]{2}{*}{ Constant } & $-3.313^{*}$ & -1.245 & 2.029 & 0.623 & 2.742 & 0.738 \\
\hline & {$[1.94]$} & {$[0.23]$} & {$[1.00]$} & {$[0.46]$} & [1.11] & [0.38] \\
\hline Age, age squared, gender & yes & yes & yes & yes & yes & yes \\
\hline $\begin{array}{l}\text { Income, education, occup. status, } \\
\text { marital status, social capital, attitudes }\end{array}$ & yes & no & yes & no & yes & no \\
\hline Observations & 13531 & 18270 & 33630 & 43187 & 33630 & 43187 \\
\hline Number of countries & 11 & 12 & 27 & 29 & 27 & 29 \\
\hline R-squared & 0.1216 & 0.0183 & 0.1764 & 0.0779 & 0.1750 & 0.0708 \\
\hline
\end{tabular}

27. What are the mechanisms responsible for this counterintuitive finding? Traditionally, sociologists' and economists' empirical analyses of social mobility ('social fluidity') suggest that education plays an important role in determining social class. In particular, education is viewed as a decisive mediating factor for the impact of class origin on class destination (class origin $=>$ education $\Rightarrow>$ class destination). Intuitively, it may be appealing to think that by increasing educational mobility, social mobility will be increased. However, the empirical analyses presented in Breen (2004) show that between 1970 and 2000 social mobility has not converged at all in 11 European countries (including Israel) and cross-national variation remains substantial. In addition, it is argued that educational mobility and meritocratic principles need to be changed simultaneously in order to achieve a higher overall social mobility: Breen (2004) states that a policy to increase enrolments in higher education with a view to increasing social mobility will not be effective if this also changes the degree to which segmented labour markets operate on a meritocratic basis. Indeed, as more people get better educated, the origin classdestination class-link at these higher levels of education might even strengthen (as shown by Vallet (2004) for France). In such case, social connections, family culture, as well as the preferences and goals among children formed by the family may become decisive for success in the labour market, leading to the opposite policy effect than the intended one, causing lower social mobility (Corak, 2006). ${ }^{19}$ In sum, the extent of the effect of educational mobility on social mobility depends on the strength of the link between education level and class destination, which varies greatly across countries.

28. In the later part of this paper, the question of the linkage between mobility in educational attainment and mobility in the labour market will be further discussed.

19. For literature on changes in educational mobility in industrialized countries (associations between class origin and educational attainment), see Breen and Jonsson (2005). Notably, for the USA, several studies report no decrease in educational inequality. 
DELSA/ELSA/WD/SEM(2009)21

\subsection{Political ideology}

\section{Left-wing oriented persons}

29. Traditionally, leftist oriented persons are believed to prefer equal outcomes, e.g. low degrees of inequality. Such equalization of outcome may well be realized by government interventions that favour the disadvantaged and socially marginalized, e.g. through redistribution of market incomes through taxation and welfare transfers. However, a more equal distribution of market-generated earnings is also believed to be achieved by equalization of levels of educational attainment, making educational attainment independent of parental background and breaking up the linkage between parental generation income inequality and the present generation income distribution (see OECD 2008, p.216). Low social mobility can reinforce income inequality driving its continuing increase over time (see OECD 2008 p.214 and p.27). In this view, social mobility in terms of labour market outcomes can be viewed as indication that poverty transmission across generations has successfully been broken up: "if the degree of intergenerational transmission of disadvantage can be reduced, the aptitudes and abilities of everyone in society are more likely to be used efficiently, thus promoting both growth and equity" (OECD 2008, p.214). Thus, social mobility may, in the long run, be conducive to equity.

30. That leftist oriented persons are inequality averse to a stronger degree compared to conservative persons has been shown by e.g. Alesina et al. (2004) for both the US and Western Europe. While there is no direct empirical evidence on the linkage between preferences for social mobility and political orientation, Clark et al. (2008) suggest a positive linkage between own-experienced individual upwardmobility and being leftist. Specifically, they have shown that persons with an improved socio-economic status in the labour market, compared to that of their parents, measured by the Goldthorpe index, are more likely to be pro-redistribution, pro-public sector and vote for leftist parties. This finding does not contradict that socio-economic status per se is positively associated with being conservative (empirically supported by Piketty 1995, Persson and Tabellini 1996, Alesina and La Ferrara 2005), this being controlled for in the modelling. ${ }^{20}$

31. In sum, improving social mobility should be in accordance with leftists' policy goals, contributing to their subjective well-being. ${ }^{21}$

\section{Right-wing oriented persons}

32. On the other hand, as argued by Alesina and La Ferrara (2005), a conservative view-point may well be in line with a belief that market outcomes are performance-based, and thus 'fair', opposing too great a degree of income redistribution. Similarly, Clark and D'Angelo (2008) argue that individuals will

20. This finding contradicts their intuitive prediction that social climbers would express a more conservative political ideology, aiming at not having to share their newly gained property with the 'have-nots'. As their findings are derived from the British Household Panel, the observed linkages between own past mobility and political self-positioning may well be specific to the British culture.

21. Based on these arguments, social mobility should be negatively correlated with income inequality, possibly stronger with market-generated pre-transfer income inequality than with inequality in disposable income after corrective redistribution through the government. However, correlations of social mobility in the labour market with pre- and post-transfer income inequality of mid-2000 are rather comparable in size $(\rho=$ -0.69 and -0.71 , respectively) (see also OECD, 2008, p.13 for Gini coefficients based on disposable income $(\rho=-0.68)$. In contrast, correlations between mobility in educational attainment and market income inequality of mid-2000 are not significant, while being significantly negatively correlated with final income inequality (when Italy is excluded as outliers). Possibly, mobility in educational attainment captures population preferences for equalizing market outcomes. See also Table A9. 
be more conservative the higher their own social upward-mobility (having achieved a higher socioeconomic position compared to their parents' standing). ${ }^{22}$ Indeed, Alesina and La Ferrara (2005) show that believing in 'hard work' as main factor for getting ahead is associated with a preference for less redistribution in the US. Using individual data from the General Social Survey, they also report a negative association between having a personal history of upward mobility in the labour market and preferences for redistribution. ${ }^{23}$ Also Corneo and Gruener (2002) identify a linkage between (subjectively perceived) upward mobility and the call for less redistributive activities for 7000 persons from 12 developed, mostly OECD countries. Higher social mobility would then be interpreted as a stronger personal achievement reflection of socio-economic status, and being in line with conservative political preferences. ${ }^{24}$

33. Taken altogether, social mobility may be in accordance with a rightwing political ideology, and be conducive to subjective well-being of politically conservative persons.

\section{Empirical Analysis: Social mobility effects for SWB by political ideology}

34. To analyze the heterogeneity of SWB effects of social mobility in society by political ideology, Table 4 estimates the full model that includes all socio-demographic controls for two ideology-specific sub-samples. Based on a 10-point scale of political self-positioning (from 1(left) to 10 (right)), variables 'leftist' for the lower categories, and 'conservative' for the upper categories, are constructed, omitting the centrist-oriented persons. ${ }^{25}$ This approach of splitting international micro-data by self-reported political ideology follows the approach chosen by Alesina et al. (2004) who use individual-level information from the European Barometer Surveys covering 12 European countries. As argued before, since a full model including individual-specific determinants of SWB is estimated, we observe the effect of the degree of social mobility in society rather than (indirectly measured) individual, experienced social mobility. Columns 1, 3 and 5 of Table 4 display the results for the subsample of conservative persons, while columns 2, 4, and 6 present the findings for leftist individuals.

35. Table 4 shows differential SWB effects by respondent's political ideology for all three measures of social mobility - both for social mobility in the labour market and at school. Considerable differences in coefficient sizes and significance levels between columns 1, 3 and 5 and columns 2, 4 and 6 indicate that only conservative persons value social mobility positively, while leftist persons do not appear to care. For social mobility in the labour market, the marginal effect of 1.86 implies that a change from a medium persistence of earnings across generations (-0.5) to complete mobility (0), ceteris paribus and causally interpreted, increases a conservative respondent's SWB, on average, by almost an entire satisfaction category. For mobility in terms of educational attainment, marginal effects are almost identical to those observed for the full population (Table 3). Potential explanations for the observed heterogeneity of the

22. Corneo and Gruener (2002) argue that due to growing heterogeneity in milieu and rising probabilities of matches with persons from a low-class family background in the marriage market, high-income persons are more likely to oppose social mobility and income redistribution.

23. Social mobility is measured as the intergenerational difference in job prestige. Notably, for social mobility proxied by the difference in years of education a pro-redistribution effect is observable, controlling for individual level of education. See also Alesina and Angeletos (2002) and Fong (2001) for similar findings.

24. Particularly, this linkage may depend on the belief in whether their success was caused by 'luck' or 'effort'. See also Alesina and Angeletos (2002) and Fong (2001) on such determinants of preferences for income redistribution and welfare spending.

25. We define 'leftist' as those persons positioning themselves between 1 and 4 (ca. 10'000), and 'conservative' for those between 6 and 10 (ca. 16'000). Notably, about $25 \%$ of all persons in the full sample rank themselves as ' 5 ' (about 12'000). Applying a more restrictive definition of 'conservative' (for values 8,9, and 10; 6'000 individuals), yields coefficients similar to those reported in columns 1, 3, and 5 (1.26, 0.014, and 0.012). 
social mobility effects by political ideology on subjective well-being will be discussed at the end of this paper in section 5 .

Table 4: Heterogeneity by political ideology

\begin{tabular}{|l|c|c|c|c|c|c|}
\hline & 1 & 2 & 3 & 4 & 5 & 6 \\
\hline & Cons. & Leftist & Cons. & Leftist & Cons. & Leftist \\
\hline Labour market mobility & & & & & & \\
\hline & $1.864^{*}$ & $0.908+$ & & & & \\
\hline Educational mobility (mother) & {$[2.53]$} & {$[1.95]$} & & & & \\
\hline & & & $0.014^{* *}$ & 0.008 & & \\
\hline Educational mobility (father) & & {$[2.95]$} & {$[1.26]$} & & \\
\hline & & & & $0.012^{*}$ & 0.007 \\
\hline Log(NNI) & & & & & {$[2.34]$} & {$[1.18]$} \\
\hline & $1.962^{*}$ & $0.652+$ & 0.277 & $0.973^{* *}$ & 0.212 & $0.933^{* *}$ \\
\hline Constant & {$[3.07]$} & {$[1.89]$} & {$[1.68]$} & {$[4.95]$} & {$[1.09]$} & {$[4.23]$} \\
\hline & $-12.169+$ & 0.848 & $5.752^{* *}$ & -2.252 & $6.446^{* *}$ & -1.818 \\
\hline Observations & {$[1.85]$} & {$[0.26]$} & {$[3.23]$} & {$[1.01]$} & {$[3.02]$} & {$[0.73]$} \\
\hline Number of countries & 1680 & 3420 & 5209 & 7705 & 5209 & 7705 \\
\hline R-squared & 11 & 11 & 27 & 27 & 27 & 27 \\
\hline
\end{tabular}

Notes: Weighted OLS regressions for 44'000 persons from 30 OECD countries. Dependent variable: Life satisfaction measured on a 10-point scale. 'Labour market mobility' is derived from intergenerational earnings elasticity, while 'educational mobility

(mother/father)' is measured in terms of maternal/paternal education-dependence. Higher values indicate more social mobility.

Subsamples by political self-positioning on a 10-point scale, with categories $1-4$ representing 'leftist', categories $6-10$ representing

+'conservative', and 'centrist' as excluded category. Standard errors corrected for within-country correlation. ' '*', '*', '+' denote significances at the 1,5 and 10 percent levels, respectively.

\subsection{The SWB effects of perceived social mobility}

36. As Alesina et al. (2004) suggest, it may be perceived rather than actual social mobility in society that affects one's assessment of society's state and matters to subjective well-being. Indeed, while income inequality was reported to affect subjective well-being a little in the US, but to lower it substantially in Western European countries, actual social mobility was rather higher in Europe (Alesina et al., 2001; see also Table 1, and OECD, 2008, pp. 204 cont.). Building on this argument, objective measures of actual social mobility in society (reflecting equality in opportunities) may not approximate subjective, perceived social mobility. To test this assumption we construct a measure of perceived social mobility using three items from the WVS that relate to the perceived fairness of the education system and income mobility, with the first component dominating, as described in the data section. The availability of this measure for 30 '000 individuals only restricts the sample to 25 OECD countries. Simple correlations suggest that our measures of actual social mobility and perceived social mobility are hardly correlated, with a correlation coefficient not exceeding 0.14 in absolute terms. ${ }^{26}$

\section{Empirical analysis: social mobility perceptions in OECD countries}

37. Table 5 provides estimation results when mobility perceptions are included to the baseline model. Columns 1 and 2 display the results when actual social mobility is assessed in terms of labour market outcomes, while columns 3 through 6 assess it in terms of educational attainment. All models in Table 5 clearly show that an increase in perceived social mobility is associated with a gain in subjective well-being

26. The correlations of perceived micro-level social mobility perception with country-level mobility in the labour market, and educational mobility, are $\rho=0.14,-0.009$ (mother), and- 0.011 (father), respectively. 
of roughly $1 / 3$ of a SWB category ( 0.25 and 0.34$)$, on average. The size of this effect lies in the medium band and is comparable to that of e.g. being married, being separated, attending a religious service more than weekly, or trusting one's peers (see Table A2 of the Appendix).

38. A comparison with the baseline results of Table 3 reveals that perceived social mobility in Table 5 does not correlate with actual social mobility measured by the elasticity of one's own earnings to one's parents' earnings: the coefficient estimates in models 1 and 2 of Table 5 are almost identical in size compared to those in columns 1 and 2 of Table 3. Thus, perceived social mobility does not appear to mediate the SWB effects of intergenerational wage elasticity. In contrast, the impact of actual equality in education in columns 3 to 6 is smaller than those observed in the baseline models of Table 3 .

Table 5: Perceived social mobility

\begin{tabular}{|c|c|c|c|c|c|c|}
\hline & 1 & 2 & 3 & 4 & 5 & 6 \\
\hline \multirow[t]{2}{*}{ Perceived social mobility } & $0.253^{* *}$ & $0.340^{* *}$ & $0.322^{* *}$ & $0.444^{* *}$ & $0.318^{* *}$ & $0.432^{* *}$ \\
\hline & {$[7.15]$} & [6.49] & [6.83] & [6.38] & {$[6.85]$} & [6.51] \\
\hline \multirow[t]{2}{*}{ Labour market mobility } & $1.246^{* *}$ & $1.999^{*}$ & & & & \\
\hline & [3.39] & {$[2.55]$} & & & & \\
\hline \multirow[t]{2}{*}{ Educational mobility (mother) } & & & -0.001 & 0.006 & & \\
\hline & & & {$[0.13]$} & [1.05] & & \\
\hline \multirow[t]{2}{*}{ Educational mobility (father) } & & & & & -0.004 & -0.000 \\
\hline & & & & & [0.91] & {$[0.03]$} \\
\hline \multirow[t]{2}{*}{$\log (\mathrm{NNI})$} & 0.991 & -0.005 & $1.229^{* *}$ & $1.108^{* *}$ & $1.356^{* *}$ & $1.203^{* *}$ \\
\hline & [1.34] & {$[0.01]$} & [7.64] & [7.64] & [6.94] & [6.70] \\
\hline \multirow[t]{2}{*}{ Constant } & -2.619 & 8.011 & $-4.215^{*}$ & $-3.355^{*}$ & $-5.572^{*}$ & $-4.421^{*}$ \\
\hline & {$[0.35]$} & [1.31] & {$[2.59]$} & {$[2.28]$} & {$[2.84]$} & {$[2.43]$} \\
\hline Age, age squared, gender & Yes & yes & yes & yes & yes & yes \\
\hline $\begin{array}{l}\text { Income, education, occup. status, } \\
\text { marital status, social capital, attitudes }\end{array}$ & Yes & no & yes & no & yes & no \\
\hline Observations & 8485 & 11728 & 19366 & 25126 & 19366 & 25126 \\
\hline Number of countries & 9 & 10 & 21 & 23 & 21 & 23 \\
\hline R-squared & 0.1340 & 0.0278 & 0.1909 & 0.0898 & 0.1914 & 0.0885 \\
\hline
\end{tabular}

\section{Testing components of social mobility perceptions}

39. It may be argued that the measure of perceived social mobility is biased because of the dominance of the confidence-in-education-system-component in it. ${ }^{27}$ Table A5 of the Appendix uses an alternative measure of perceived social mobility which is based on the 'escape from poverty is possible' and 'success is through effort, not luck' components. This definition of perceived social mobility reduces the regression sample to 4'000 persons in 3 countries. These regressions, however, yield identical results. Controlling for actual social mobility, which varies only at the country level, individual mobility perceptions appear clearly conducive to SWB. Due to the small number of countries in this subsample no

27. OECD (2008) argues that investment in human capital is a major policy to overcome transmission of poverty from one generation to the next. Thus, confidence in education may well approximate the perceived success of such government activities. However, confidence in the education system may still be considered as a rather far-fetched measure of perceived social mobility. 
conclusion with respect to the impact of actual social mobility can be made. The positive association of subjective mobility perceptions with SWB also holds for the same subsample in Table A6 of the Appendix when the two components of this perceived social mobility measure are tested separately (replacing actual social mobility measures with simple country fixed effects) .

\subsection{Income inequality and $S W B$}

40. Most recent happiness research suggests that the well-being effects of individual's socioeconomic position are conditional on her perceptions of fairness, aspirations, and expectations. Alesina et al. (2004) and Senik (2008) suggest that the SWB effects of income inequality are heterogeneous, depending on perceived and actual social mobility in a society. Bjørnskov, Dreher, Fischer, and Schnellenbach (2008) test the effects of general fairness perceptions for the differential impact of income inequality for a world sample. Effects of income inequality on subjective well-being may also differ whether pre-redistribution or post-transfer- and -tax -income redistribution is analyzed. While the first reflects the income gained in the market process (market income), the second mirrors income disposable for actual consumption after re-distribution through taxes and transfers (final income). This section analyzes the associations between income inequality, actual and perceived social mobility for OECD countries. The pre- and post-transfer income inequality measures are both obtained from OECD (2008) and available for around 2000 and mid-2000.

\section{Simple correlations between population happiness and income inequality}

41. Graphs 3a to $3 \mathrm{~d}$ illustrate the simple correlations between the population share of respondents in the three highest categories on the life satisfaction scale and the four different measures of income inequality. All fitted regression lines suggest that correlations are negative, with greater income inequality being associated with lower population well-being. Slopes appear substantially steeper for final income inequality measures. Indeed, correlation coefficients are significant for final inequality alone, but not for market income inequality prior to redistributive activities of the government. ${ }^{28}$

\section{Income inequality and individual SWB}

42. The multivariate analysis in Table 6 supports the findings based on the simple correlations. Table 6 presents the baseline model of Table 5 augmented with two measures of income inequality in society, the Gini coefficient prior and after redistributive government intervention have taken place. For simplicity, we term the first market income inequality, and the second final income inequality, with final income viewed as good proxy for consumption. For reasons of sample size, in columns 1 and 2 of Table 6 Gini coefficients from around 2000 are employed, the time the survey data were collected, while columns 3 to 4 test those of mid-2000, which are closer to the time when our measures of labour market mobility were collected. The correlation of the inequality measures across time are substantially high (about $\rho=$ $0.9)$, while pre- and final income inequality in OECD countries are correlated to a considerably lower extent $(\rho=0.4-0.5){ }^{29}$

28. Correlation coefficients for market income inequality in 2000 (2005) and final income inequality in 2000 (2005) are $-0.21(-0.29)$ and $-0.61 * *(-0.39 *)$, respectively. '**' and '*' denote statistical significance at the 1 and 5 percent levels, respectively.

29. The correlation coefficients across time for market and final income inequality are 0.93 and 0.89 , respectively. The correlation coefficients of pre- and post-transfer income inequality for the years 2000 and 2005 are 0.38 and 0.46 , respectively. The full model presented in Table 6 excludes individual income as this variable is missing for two countries (Portugal, Norway). 
Graph 3a: Consumption inequality of 2005 and Subjective Well-Being in OECD countries

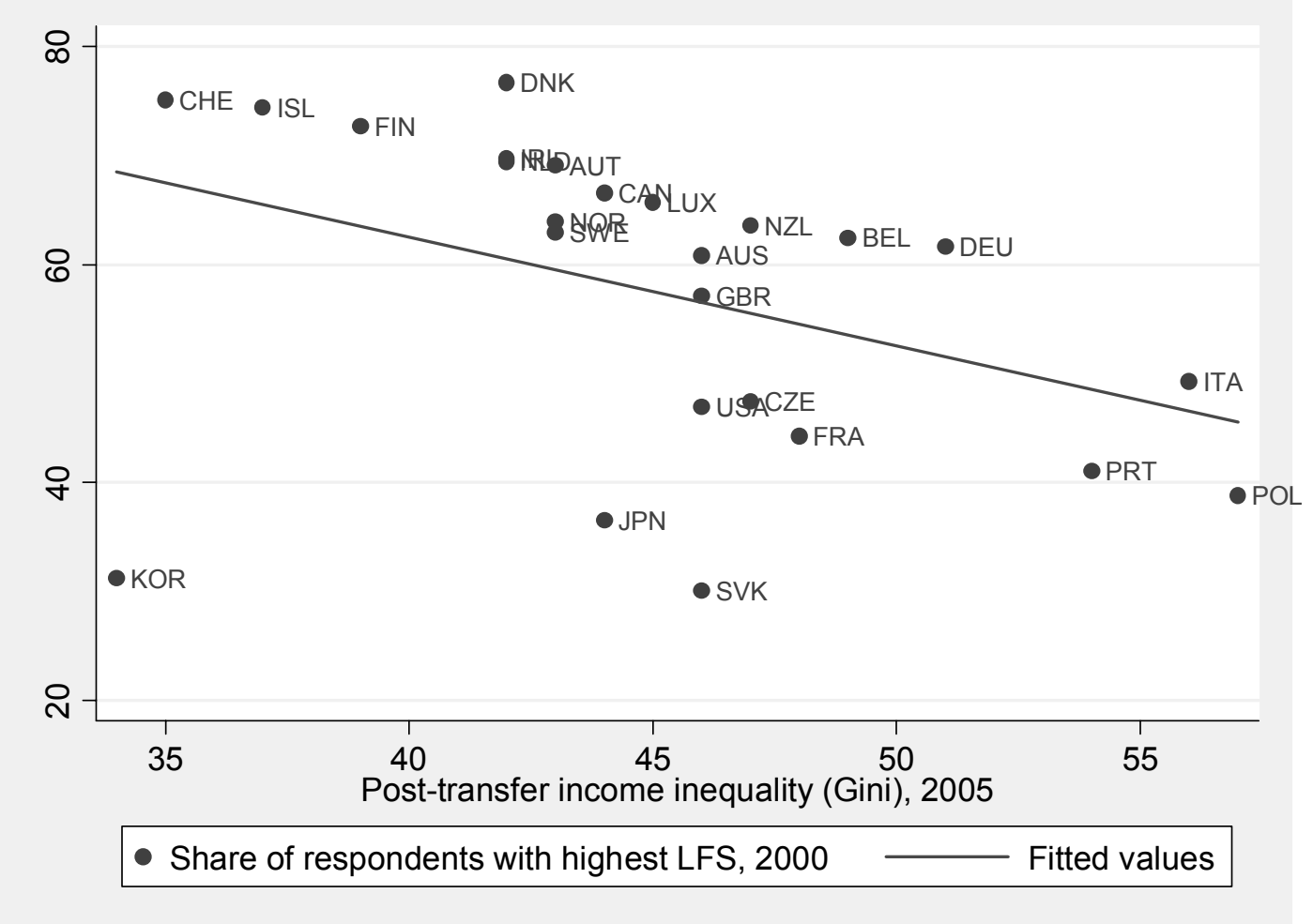

Graph 3b: Consumption inequality of 2000 and Subjective Well-Being in OECD countries

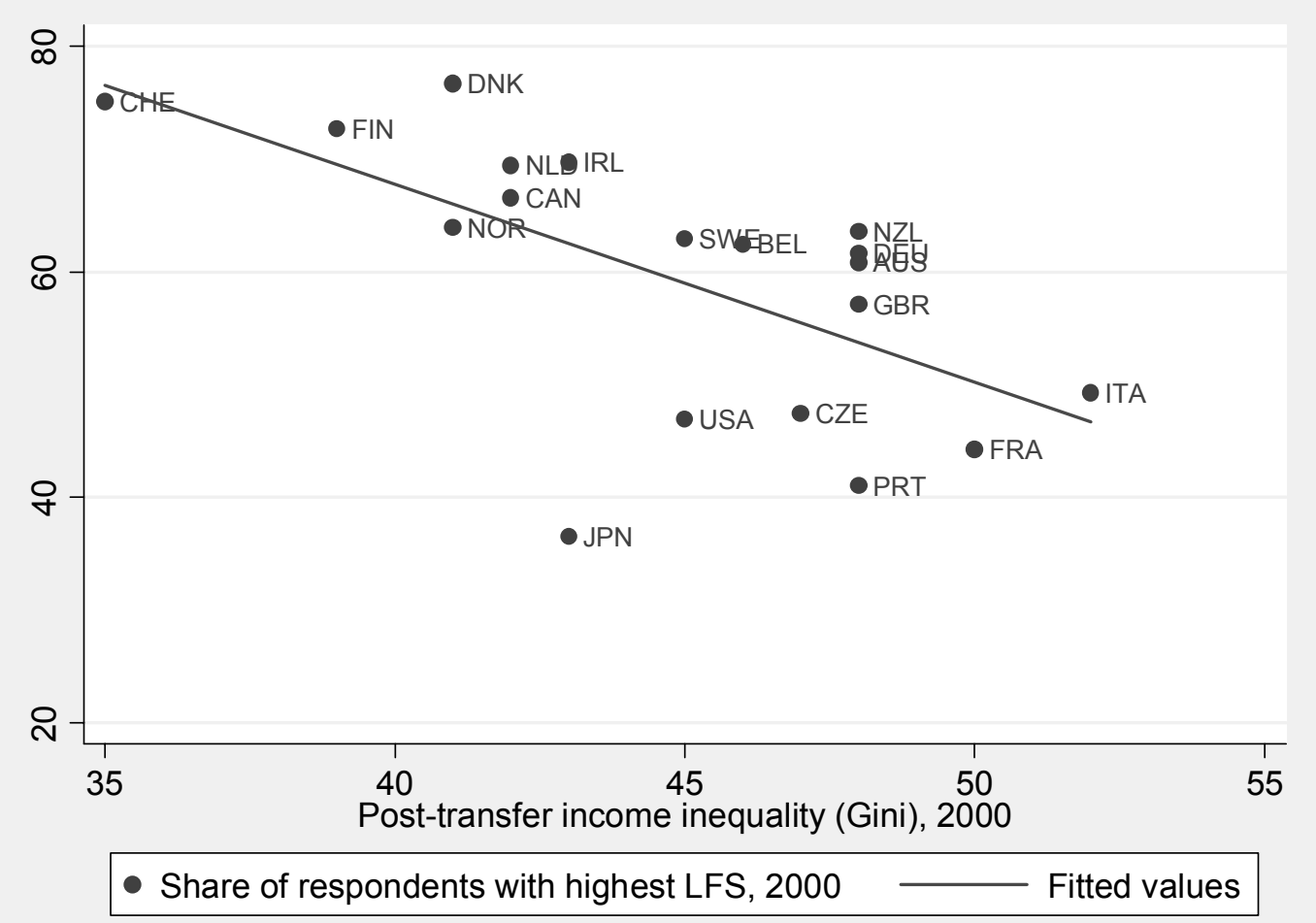


Graph 3c: Market income inequality of 2005 and Subjective Well-Being in OECD countries

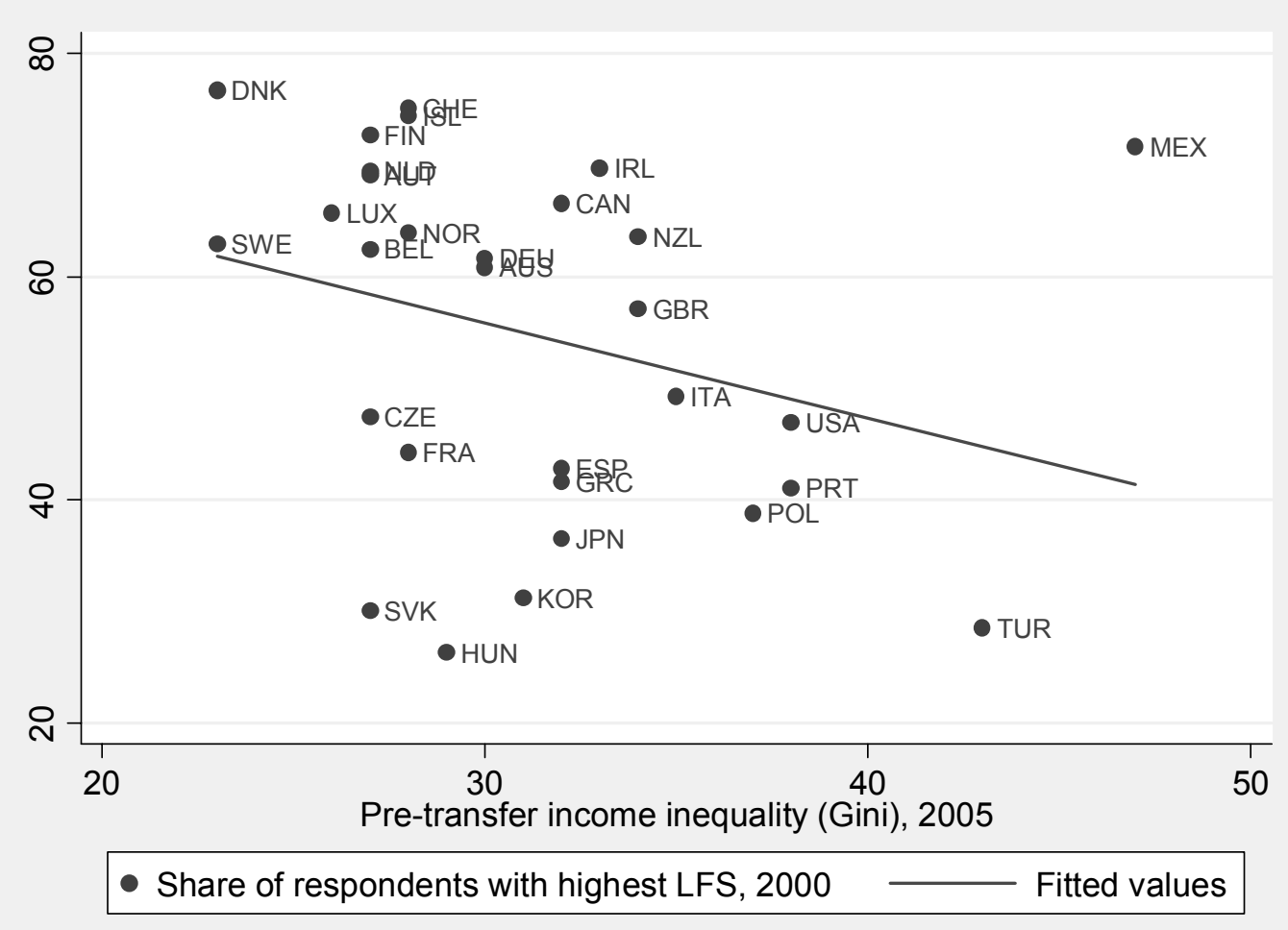

Graph 3d: Market income inequality of 2000 and Subjective Well-Being in OECD countries

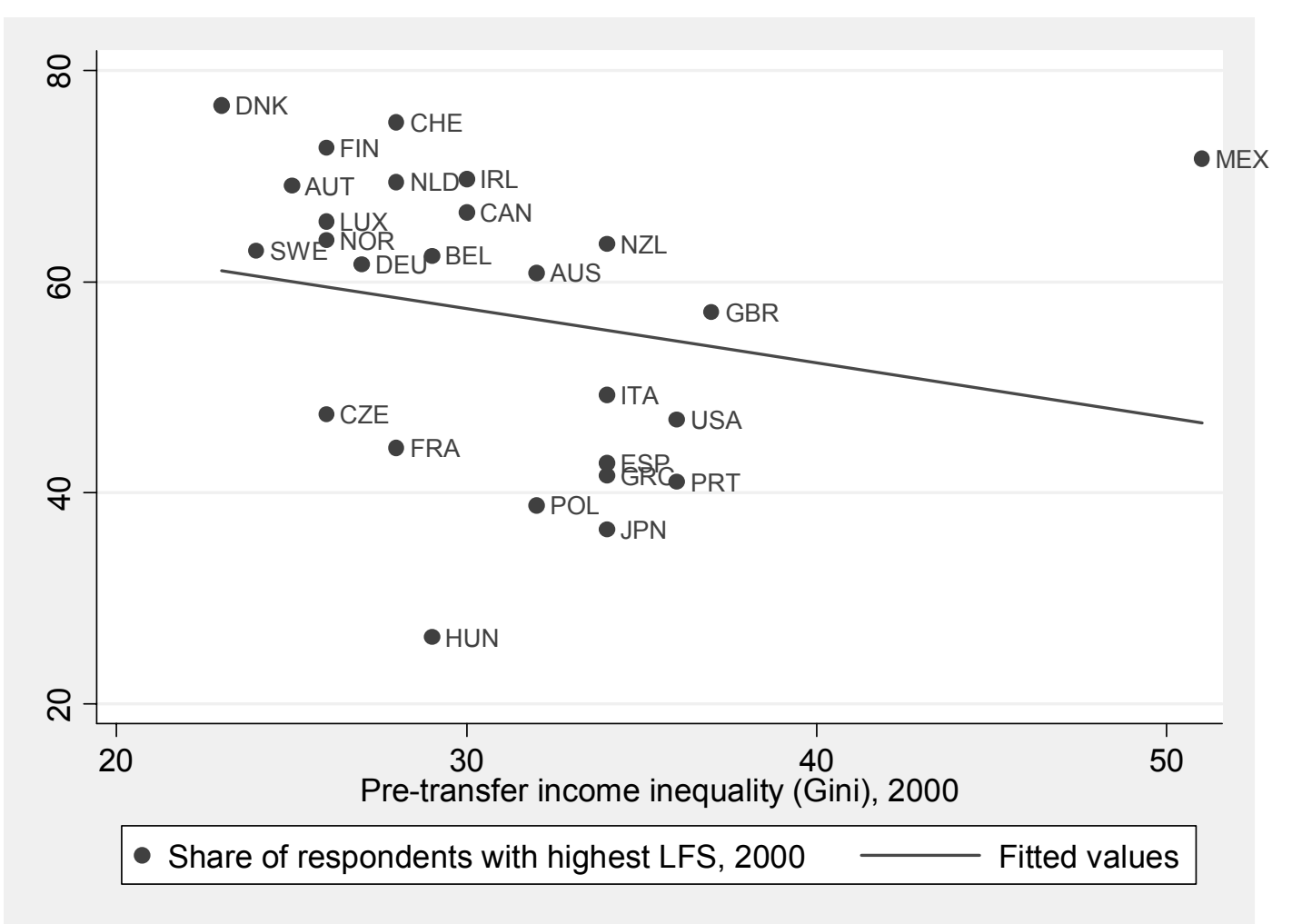


43. Table 6 shows that pre-transfer income inequality does not affect subjective well-being of persons living in OECD countries, whether measured around 2000 or around 2005 (columns 1 and 3). In contrast, final income inequality proxying disposable income around 2000 is negatively associated with life satisfaction, which is not the case if 2005 values are employed. The coefficient estimate of -0.042 suggests that an increase in final income inequality by 1 percentage point is associated with life satisfaction which is lower by roughly $5 \%$ of a category; on the other hand, a decrease by about 1 SWB category is associated with a rise in inequality by roughly 25 percentage points. Further analysis suggests that the results differ for 2000 because of the smaller country sample, which excludes Austria, Iceland, Korea, Luxembourg, Poland and the Slovak Republic: Indeed, the exclusion of Korea in column 4 yields a negative correlation which is significant at the 5 percent level (not reported). Columns 5 to 8 repeat the analysis for a subsample of countries for which the (3-component) social mobility perception variable is available. In this subsample, final income inequality is now clearly negatively associated with SWB for both time points of measurement.

44. Taken all together, the simple correlations and the multivariate analyses in Table 6 may suggest that social comparisons take place based on consumption (approximated by final, post-transfer income) rather than market-generated income. That income inequality is negatively associated with SWB in Western-European countries, which dominate in our sample, has been shown by Alesina et al. (2004) using repeated cross-sections that allow for the inclusion of country and time fixed effects.

\subsection{Perceived social mobility and income inequality}

45. Table 7 tests the heterogeneity of the income inequality effects by degree of subjective social mobility through an interaction between the Gini variables and the measure of perceived social mobility that is added to the model of Table 6 . As described in the section on data, social mobility perceptions are captured by a dichotomous variable based on three questions posed in the World Values Survey; a person is viewed as believing in that social climbing in her society was possible if she agreed to at least one of the three questions, of which the first relates to having confidence in the education system, the second asks whether lack or laziness determines financial success, and the third whether escaping poverty is possible. The first part of Table 7 employs income inequality measured around 2000 (columns 1 to 4), while the second part tests values of mid-2000 (columns 5 to 8). The odd-numbered columns always exclude the interaction term between social mobility perceptions and income inequality, while the even-numbered include it.

\section{Empirical analysis}

\section{Inequality}

46. Excluding the interaction terms, Table 7 appears to confirm the previous results of Table 6 that in OECD countries social comparisons are based on final income but are not based on market income distribution. The reason may well be that final income, which is close to actual consumption, is more likely to be observed by other members of society compared to individual market income before the redistributive government has intervened. The coefficient estimates in columns 3 and 4 are similar to that of Table 6 , with life satisfaction lowered by $5 \%$ of a category when final inequality is raised by 1 percentage point. However, inclusion of the interaction terms in the even-numbered columns 2 and 6 increases the statistical significance of market income inequality close to conventional levels. 
Table 6: Income inequality and life satisfaction in OECD countries

\begin{tabular}{|c|c|c|c|c|c|c|c|c|}
\hline & 1 & 2 & 3 & 4 & 5 & 6 & 7 & 8 \\
\hline \multirow[t]{2}{*}{ Market Gini 2000} & 0.019 & & & & -0.015 & & & \\
\hline & {$[0.77]$} & & & & {$[0.98]$} & & & \\
\hline \multirow[t]{2}{*}{ Final Gini 2000} & & $-0.042^{* *}$ & & & & $-0.051^{* *}$ & & \\
\hline & & {$[4.23]$} & & & & [3.35] & & \\
\hline \multirow[t]{2}{*}{ Market Gini 2005} & & & 0.028 & & & & 0.006 & \\
\hline & & & {$[1.07]$} & & & & {$[0.36]$} & \\
\hline \multirow[t]{2}{*}{ Final Gini 2005} & & & & -0.008 & & & & $-0.029+$ \\
\hline & & & & {$[0.57]$} & & & & {$[1.93]$} \\
\hline \multirow[t]{2}{*}{$\log (\mathrm{NNI})$} & $0.812^{*}$ & 0.263 & $0.952^{* *}$ & $1.064^{* *}$ & $1.070^{* *}$ & 0.28 & $1.175^{\star *}$ & $0.923^{* *}$ \\
\hline & {$[2.78]$} & {$[1.50]$} & {$[4.47]$} & {$[4.92]$} & {$[4.08]$} & {$[1.10]$} & {$[5.49]$} & [3.35] \\
\hline Other micro controls & yes & yes & yes & yes & yes & Yes & yes & yes \\
\hline \multirow[t]{2}{*}{ Constant } & -1.025 & $6.717^{* *}$ & -2.695 & -2.723 & -2.654 & $7.071^{*}$ & $-4.263+$ & -0.186 \\
\hline & {$[0.32]$} & [3.25] & {$[1.10]$} & {$[1.02]$} & {$[0.94]$} & {$[2.70]$} & {$[1.72]$} & {$[0.06]$} \\
\hline Observations & 34227 & 25082 & 41824 & 31972 & 25785 & 19423 & 29079 & 24980 \\
\hline R-squared & 0.1074 & 0.1051 & 0.1359 & 0.1279 & 0.1295 & 0.1035 & 0.1513 & 0.1261 \\
\hline No of countries & 26 & 19 & 30 & 25 & 21 & 15 & 24 & 20 \\
\hline
\end{tabular}

Notes: Weighted OLS regressions for 44'000 persons from 30 OECD countries. Dependent variable: Life satisfaction measured on a 10-point scale. Standard errors corrected for within-country correlation. ' $*$ ' denote significances at the 1,5 and 10 percent levels, respectively. Columns 5 to 8 use a subsample for which the social mobility perception measure is available. 'Other micro controls' include age, age squared, gender, education, occupational status, marital status, social capital, and attitudes. See table A2 of the Appendix. 


\section{Mobility perceptions}

47. The findings for social mobility perceptions (dichotomous indicator) in Table 7 are rather ambiguous. Columns 1, 3, 5, and 7, which exclude any interaction, appear to confirm that perceived social mobility is positively associated with subjective well-being. Believing that the society one lives in allows for social climbing is associated with a gain of one third of a life satisfaction category. However, the remaining models suggest that such perceptions do not play a role for SWB directly, but only indirectly through their interplay with market or final income inequality, as described below.

\section{Interplay between inequality and mobility perceptions}

48. As regards market income inequality, the most important finding in Table 7 is its positive and significant interaction with perceived social mobility (columns 2 and 6), while the signs of the market inequality coefficients are negative. Thus, as conjectured by Alesina et al. (2004), having a perception of being in a socially mobile society mitigates the well-being lowering impact of income inequality. Given the dichotomous nature of the perceived social mobility measure, in this sample the overall marginal effect of market income inequality becomes positive in a subjectively socially mobile society (e.g. column $6,-0.010+0.027=0.017)$.

49. In contrast, as regards final income inequality, at first sight the positive interaction between final income inequality and perceived social mobility is not significant at conventional levels (columns 4 and 8). However, this finding may well be caused by the extremely high correlation between the interaction term and social mobility perception measures; indeed, in both cases tests of joint significance reject the null hypothesis of both coefficient estimates being zero. ${ }^{30}$ On the other hand, in both models 4 and 8 the $t-$ statistics are considerably larger for the interaction terms compared to that of social mobility perceptions estimates, suggesting that the interaction term dominates.

50. Given the negative association of final income inequality with subjective well-being in both models, the results in Table 7 suggest that social mobility perceptions mitigate this effect of final income inequality. In column 4 (column 8), given the magnitude of the positive interaction term of $0.005(0.010)$, the dichotomous nature of perceived social mobility measure, and the size of the negative coefficient on income inequality of $-0.050(-0.034)$, in OECD countries the total marginal effect of final income inequality on SWB remains always negative, reaching values of $-0.045(-0.024) .^{31}$

\section{Subsample analysis}

51. The models of Table 7 have been re-estimated for a much smaller sample of 9 to 10 countries in which intergenerational wage elasticity can be observed (see Table A7, see also Table 8). Columns 2, 4, 6 and 8 in Table A7 of the Appendix appear to corroborate the previous finding that social mobility perceptions influence SWB via their interaction with inequality rather than directly. However, in contrast to the findings in the larger sample in Table 7, all models 1 to 8 both pre- and post-transfer income inequality do not confirm that social comparisons take place with respect to levels of consumption only, as both market and final income inequality appear now negatively associated with subjective well-being,

\footnotetext{
30. The correlation of the interaction term with the social mobility measure exceeds 0.96 for market income inequality and 0.98 for final income inequality.

31. Qualitatively similar results are obtained for a subsample of countries for which actual social mobility data measured as intergenerational wage elasticity are available. Results are available on request.
} 
with coefficients just missing the 10 percent significance levels. ${ }^{32}$ Also in contrast to the larger sample results, none of the coefficients on the interaction terms are significant. Again, the considerably high correlation between social mobility perceptions and its interaction with income inequality may well inflate standard errors. F-tests of joint significance at the bottom of the table confirm this conclusion. Thus, in this small subsample of Table A7 we cannot exclude the possibility that both social mobility perceptions and their interaction with income inequality are important determinants of individual SWB. ${ }^{33}$

\section{Summary}

52. Table 7 and A7 show that both market and final income inequality per se are negatively associated with SWB; however, social comparisons appear stronger for consumption levels than for pretransfer earning levels. On the other hand, social mobility perceptions interact (statistically) in a more pronounced way with market-generated income inequality than with the final income distribution.

53. Both Tables 7 and A7 suggest that perceived social mobility is not relevant for people's wellbeing per se. However, high market income inequality has even a positive effect on SWB when opportunities in society are perceived as more or less fair and equal, but remains negative for subjectively socially immobile societies. In contrast, the SWB-lowering effect of final income inequality becomes only a bit smaller in a subjectively fair society. Possibly, in a subjectively fair society unequally distributed income may reflect own future earnings or consumption potentials (Alesina et al., 2004).

\subsection{Actual social mobility and income inequality}

54. Table 8 tests interactions of actual social mobility, measured in terms of intergenerational earnings elasticity, with income inequality. The social mobility measure has been recoded so that higher values indicate more mobility in the labour market. Columns 1 to 4 display the results when income inequality measured in mid-2000 is employed, while the remaining columns use the inequality measure of 2000. Columns 1 and 2 test the interplay between actual social mobility and market and final income inequality and, while columns 3 and 4 add an interaction between perceived social mobility with income inequality. Due to missing values in the labour market mobility variable, this specification includes only twelve countries, excluding the Eastern European states. Potentially, the findings that follow are representative for Western Europe only. ${ }^{34}$ Due the larger sample size, the focus of the results description is set on the inequality indicators of 2005 .

32. Significance at the 10 percent level is reached only in column 7 for final income inequality in mid-2000. Income inequality varies only across countries which hinders statistical identification in case the number of countries is below 30 .

33. Correlation coefficients of pre- and post-transfer income inequality for 2000 (2005) are with $0.49(0.53)$ considerably low to exclude the interpretation that both inequality measures simply approximate each other. Correlations between the interaction term and social mobility perceptions are $\rho=0.98$; in contrast, income inequality and its interaction with social mobility perceptions are de facto no correlated at all $(\rho$ about -0.02).

34. The twelve countries include Australia, Canada, Germany, Denmark, Spain, Finland, France, United Kingdom, Italy, Norway, Sweden, and the United States. 
Table 7: Perceived social mobility and income inequality

\begin{tabular}{|c|c|c|c|c|c|c|c|c|}
\hline & 1 & 2 & 3 & 4 & 5 & 6 & 7 & 8 \\
\hline Perc. soc. mob. & $0.337^{* *}$ & -0.209 & $0.306^{* *}$ & 0.074 & $0.331^{* \star}$ & $-0.480+$ & $0.275^{\star *}$ & -0.200 \\
\hline & {$[7.37]$} & {$[0.83]$} & {$[4.97]$} & {$[0.15]$} & {$[6.91]$} & {$[2.03]$} & {$[6.43]$} & {$[0.57]$} \\
\hline Market Gini 2000 & -0.011 & -0.023 & & & & & & \\
\hline & {$[0.76]$} & {$[1.60]$} & & & & & & \\
\hline Perc. soc. mob. ${ }^{*}$ market Gini 2000 & & $0.018^{*}$ & & & & & & \\
\hline & & {$[2.15]$} & & & & & & \\
\hline Final Gini 2000 & & & $-0.046^{\star *}$ & $-0.050^{*}$ & & & & \\
\hline & & & {$[3.01]$} & {$[2.78]$} & & & & \\
\hline Perc. soc. mob. ${ }^{*}$ final Gini 2000 & & & & 0.005 & & & & \\
\hline & & & & {$[0.45]$} & & & & \\
\hline Market Gini 2005 & & & & & 0.009 & -0.010 & & \\
\hline & & & & & {$[0.51]$} & {$[0.63]$} & & \\
\hline Perc. soc. mob. ${ }^{*}$ market Gini 2005 & & & & & & $0.027^{* *}$ & & \\
\hline & & & & & & [3.52] & & \\
\hline Final Gini 2005 & & & & & & & $-0.026+$ & $-0.034^{*}$ \\
\hline & & & & & & & {$[1.76]$} & [2.39] \\
\hline Perc. soc. mob. * final Gini 2005 & & & & & & & & 0.010 \\
\hline & & & & & & & & [1.30] \\
\hline $\log (\mathrm{NNI})$ & $1.069^{* *}$ & $1.076^{* *}$ & 0.249 & 0.25 & $1.174^{\star *}$ & $1.179^{* \star}$ & $0.938^{\star *}$ & $0.942^{\star *}$ \\
\hline & {$[4.13]$} & {$[4.16]$} & [1.03] & [1.03] & {$[5.54]$} & {$[5.59]$} & [3.41] & {$[3.41]$} \\
\hline Other micro controls & Yes & yes & yes & yes & y & y & Yes & yes \\
\hline Constant & -2.991 & -2.697 & $6.905^{*}$ & $7.077^{*}$ & $-4.567+$ & -4.077 & -0.684 & -0.368 \\
\hline & {$[1.07]$} & {$[0.96]$} & {$[2.73]$} & {$[2.94]$} & {$[1.85]$} & {$[1.69]$} & {$[0.21]$} & {$[0.11]$} \\
\hline Observations & 25785 & 25785 & 19423 & 19423 & 29079 & 29079 & 24980 & 24980 \\
\hline R-squared & 0.1347 & 0.135 & 0.1084 & 0.1084 & 0.1561 & 0.1567 & 0.1296 & 0.1298 \\
\hline F-test (gini, perc. soc. mob.) & 31.8648 & 1.4092 & 21.6787 & 5.9149 & 24.0916 & 2.5848 & 21.5169 & 2.9911 \\
\hline $\mathrm{p}$-value & 0.000 & 0.2676 & 0.0001 & 0.0137 & 0.000 & 0.0971 & 0.000 & 0.0742 \\
\hline $\begin{array}{l}\text { F-test (interaction term, } \\
\text { perc. soc. mob.) }\end{array}$ & & 37.1461 & & 12.9704 & & 47.8504 & & 28.3023 \\
\hline p-value & & 0.000 & & 0.0007 & & 0.000 & & 0.000 \\
\hline No of countries & 21 & 21 & 15 & 15 & 24 & 24 & 20 & 20 \\
\hline
\end{tabular}

Notes: Weighted OLS regressions for $44^{\prime} 000$ persons from 30 OECD countries. Dependent variable: Life satisfaction measured on a 10-point scale. Standard errors corrected for within-country correlation. '**', '*', '+' denote significances at the 1, 5 and 10 percent levels, respectively. 'Other micro controls' include age, age squared, gender, education, occupational status, marital status, social capital, and attitudes. See table A2 of the Appendix. 


\section{Interplay between actual social mobility and inequality}

55. Column 1 of Table 8 suggests that actual social mobility in the labour market re-enforces the well-being reducing impact of market income inequality. This finding contradicts ordinary intuition that actual social mobility may offset the negative effects of a strongly skewed income distribution on SWB. Column 1 suggests that in a society with high market income inequality people would be happier if actual social mobility in the labour market was low rather than high. Column 3 suggests that this finding is robust to controlling for perceived social mobility and its interaction with income inequality. ${ }^{35}$ Column 2 shows that such an interaction is not observed when looking at final income inequality and actual social mobility (see Table 9 and its discussion below).

\section{Social mobility perceptions}

56. Columns 3 and 4 of Table 8 support the previous findings of Table 7 that social mobility perceptions per se have no association with subjective well-being, but rather play a role in their interaction with market income inequality, while no significant interaction with final income inequality is observable. ${ }^{36}$ A possible explanation is that living in a subjectively socially mobile society makes market income inequality tolerable. Again, given the relatively large negative estimate on the market Gini coefficient, perceived social mobility can only mitigate the SWB lowering effects of income inequality.

\section{Actual social mobility}

57. In contrast, actual social mobility is positively associated with subjective well-being in OECD countries when its interaction with market-generated income is taken into account (columns 2 and 4 of Table 8, discussed below). In contrast to Tables 6 and 7, particularly market income inequality appears now negatively associated with subjective well-being, while final income inequality shows no significant correlation. Further investigation shows that these effects are not driven by the smaller number of countries in the sample. ${ }^{37}$ Obviously, not taking into account the interaction of income inequality with actual social mobility creates an omitted-variable problem.

58. Taken all together, in OECD countries actual mobility affects rather how the market-generated income distribution influences subjective well-being, which is not the case for the final income distribution after redistributive government interventions.

35. In Table 8 all three estimates are jointly significant at the 1 percent level. However, calculation of total marginal effects of income inequality indicates that the interaction term does not decisively contribute to it. Table 5 has already shown that perceived social mobility and actual social mobility are rather uncorrelated.

36. An additional regression on the sample of model 4 for the subjective measure only showed that the insignificance of the mobility estimate is not driven by the inclusion of actual social mobility (and its interaction). In column 3, F-test on its joint significance with Gini at the bottom of the table is confirmative.

37. Estimating the models of Table 6 for the smaller subsample for which actual social mobility variables are available shows a negative significant association only for final income inequality, but an insignificant for market income inequality. 
Table 8: Perceived, actual social mobility and income inequality

\begin{tabular}{|c|c|c|c|c|c|c|c|c|c|c|}
\hline & 1 & 2 & 3 & 4 & 5 & 6 & 7 & 8 & 9 & 10 \\
\hline \multirow[t]{2}{*}{ Labour market mobility } & $10.055^{* *}$ & -0.838 & $10.638^{* *}$ & 1.032 & $9.880^{* *}$ & $-9.541^{*}$ & $10.736^{* *}$ & -1.647 & $10.324^{* *}$ & 1.154 \\
\hline & [3.21] & {$[0.20]$} & [3.72] & [0.23] & [3.83] & {$[2.28]$} & {$[5.28]$} & {$[0.24]$} & [3.52] & {$[0.27]$} \\
\hline \multirow[t]{2}{*}{ Market Gini 2005} & $-0.096^{*}$ & & $-0.125^{\star *}$ & & & & & & $-0.114^{* *}$ & \\
\hline & {$[2.55]$} & & {$[4.55]$} & & & & & & {$[4.25]$} & \\
\hline \multirow[t]{2}{*}{ Market Gini 2000} & & & & & $-0.106^{* *}$ & & $-0.123^{* *}$ & & & \\
\hline & & & & & {$[4.18]$} & & [6.69] & & & \\
\hline \multirow[t]{2}{*}{$\begin{array}{l}\text { Labour market mobility* market } \\
\text { Gini } 2000 / 2005\end{array}$} & $-0.298^{*}$ & & $-0.328^{* *}$ & & $-0.298^{* *}$ & & $-0.321^{* *}$ & & $-0.315^{\star}$ & \\
\hline & {$[2.81]$} & & [3.48] & & {$[3.77]$} & & {$[5.21]$} & & [3.25] & \\
\hline \multirow[t]{2}{*}{ Final Gini 2005} & & -0.018 & & -0.013 & & & & & & -0.010 \\
\hline & & {$[0.51]$} & & {$[0.32]$} & & & & & & {$[0.11]$} \\
\hline \multirow[t]{2}{*}{ Final Gini 2000} & & & & & & -0.008 & & -0.026 & & \\
\hline & & & & & & {$[0.26]$} & & {$[0.53]$} & & \\
\hline \multirow[t]{2}{*}{$\begin{array}{l}\text { Labour market mobility * final } \\
\text { Gini } 2000 / 2005\end{array}$} & & 0.024 & & -0.009 & & $0.195^{*}$ & & 0.039 & & -0.018 \\
\hline & & {$[0.26]$} & & {$[0.09]$} & & {$[2.28]$} & & {$[0.28]$} & & [0.51] \\
\hline \multirow[t]{2}{*}{ Perceived social mobility } & & & -0.045 & 0.346 & & & -0.091 & 0.248 & & \\
\hline & & & {$[0.36]$} & {$[0.90]$} & & & {$[0.57]$} & {$[0.44]$} & & \\
\hline \multirow[t]{2}{*}{$\begin{array}{l}\text { Perc. soc. mob. }{ }^{*} \text { market } \\
\text { Gini } 200 / 2005\end{array}$} & & & $0.009^{*}$ & & & & $0.010+$ & & & \\
\hline & & & {$[2.55]$} & & & & [2.12] & & & \\
\hline \multirow[t]{2}{*}{$\begin{array}{l}\text { Perc. soc. mob. }{ }^{*} \text { final } \\
\text { Gini } 2000 / 2005\end{array}$} & & & & -0.003 & & & & -0.001 & & \\
\hline & & & & {$[0.40]$} & & & & {$[0.12]$} & & \\
\hline \multirow[t]{2}{*}{$\log (\mathrm{NNI})$} & -0.281 & -0.472 & $-1.139^{* *}$ & $-1.179^{* *}$ & -0.300 & $-1.064^{*}$ & $-1.538^{* *}$ & $-1.352^{*}$ & $-1.173^{* *}$ & $-1.221^{* *}$ \\
\hline & {$[0.63]$} & {$[1.02]$} & {$[7.16]$} & [3.65] & {$[0.62]$} & [2.60] & [5.83] & [2.69] & [7.97] & {$[4.04]$} \\
\hline \multirow[t]{2}{*}{ Constant } & $13.051^{*}$ & $12.837^{*}$ & $22.408^{* *}$ & $19.667^{* *}$ & $13.469^{*}$ & $18.195^{* *}$ & $26.482^{* *}$ & $21.910^{*}$ & $22.649^{* *}$ & $20.490^{* \star}$ \\
\hline & {$[2.56]$} & {$[2.79]$} & [12.39] & {$[4.43]$} & [2.67] & [3.87] & [8.39] & [3.10] & [13.78] & [5.25] \\
\hline Observations & 17483 & 15233 & 11985 & 11985 & 17483 & 15233 & 11985 & 11985 & 11985 & 11985 \\
\hline R-squared & 0.1018 & 0.1022 & 0.1182 & 0.1139 & 0.1021 & 0.1055 & 0.1191 & 0.1151 & 0.1159 & 0.112 \\
\hline
\end{tabular}


Table 8: Perceived, actual social mobility and income inequality (cont.)

\begin{tabular}{|c|c|c|c|c|c|c|c|c|c|c|}
\hline & 1 & 2 & 3 & 4 & 5 & 6 & 7 & 8 & 9 & 10 \\
\hline $\begin{array}{l}\text { F-test (Gini, Gini *social } \\
\text { mobility, social mobility) }\end{array}$ & & 6.92 & & 1.29 & & 21.14 & & 4.52 & & 3.34 \\
\hline $\mathrm{p}$-value & & 0.0084 & & 0.3438 & & 0.001 & & 0.0390 & & 0.0765 \\
\hline $\begin{array}{l}\text { F-test (Gini *social } \\
\text { mobility, social mobility) }\end{array}$ & & & & & & 2.61 & & & & \\
\hline $\mathrm{p}$-value & & & & & & 0.1226 & & & & \\
\hline $\begin{array}{l}\text { F-test (Gini * perc.soc. mob., } \\
\text { per. soc. mob.) }\end{array}$ & & & 25.84 & 9.25 & & & 28.18 & 7.59 & & \\
\hline$p$-value & & & 0.0003 & 0.0083 & & & 0.0002 & 0.0142 & & \\
\hline $\begin{array}{l}\text { F-test (Gini, Gini * perc.soc. mob., } \\
\text { per. soc. mob.) }\end{array}$ & & & & 6.32 & & & & 7.26 & & \\
\hline $\mathrm{p}$-value & & & & 0.0166 & & & & 0.0114 & & \\
\hline No of countries & 12 & 11 & 9 & 9 & 12 & 11 & 9 & 9 & 9 & 9 \\
\hline
\end{tabular}

Notes: Weighted OLS regressions for 44 '000 persons from 30 OECD countries. Dependent variable: Life satisfaction measured on a 10-point scale. Standard errors corrected for

within-country correlation. '**', '*', '+' denote significances at the 1,5 and 10 percent levels, respectively. 'Other micro controls' include age, age squared, gender, education,

occupational status, marital status, social capital, and attitudes. See table A2 of the Appendix. Columns 9 and 10 estimate models 1 and 2 for the smaller subsamples in columns 3 and 4 . 


\section{Total effects of income inequality and actual social mobility for SWB}

59. Table 9 displays the marginal effects of income inequality and actual social mobility based on the coefficient estimates of columns 1 and columns 2 of Table 8 . Table 9 illustrates how the total marginal effect of one variable changes when the other, interacted variable takes on different values.

60. As regards market income inequality, for a mean level of intergenerational labour market mobility $(-0.30)$ the total marginal effect of inequality is negative $(-0.01)$, indicating a subjective wellbeing lowering effect of $1 \%$ of a SWB category. In the sample minimum of actual social mobility (-0.5), the inequality effect turns positive $(0.05,5 \%$ of a category on the life satisfaction scale), while for the socially most mobile society in the sample (-0.15) the SWB effect of inequality stays negative $(-0.05)$.

61. Analogously, the total marginal effect of social mobility in the labour market is positive for a low to medium level of market income inequality (e.g. measured by the sample mean), - in other words, actual social mobility is perceived as something good in societies with a low dispersion of marketgenerated income. This positive association becomes smaller as inequality rises, and may even turn negative - in countries with a high degree of income inequality, actual social mobility is, on average, perceived as something bad.

Table 9: Marginal effects of intergenerational income elasticity and market and final income inequality

\begin{tabular}{|l|c|c|c|c|c|}
\hline Variable & Obs. & Mean & Std. Dev. & Min & Max \\
\hline & & & & & \\
\hline Table 8, column 1 & & & & & -0.15 \\
\hline Elasticity & 17483 & -0.30 & 0.12 & -0.50 & -0.05 \\
\hline d SWB/d Gini & & -0.01 & & 0.05 & \\
\hline & & & & & 38.00 \\
\hline Market income inequality 2005 & 17483 & 30.54 & 3.86 & 23.00 & -1.27 \\
\hline d SWB/d labour mob. & & 0.96 & & 3.20 & \\
\hline & & & & & \\
\hline Table 8, column 2 & & & & & -0.5 \\
\hline & & & & -0.0495 & -0.04635 \\
\hline Labour market mobility & 15233 & -0.30133 & 0.131896 & \\
\hline d SWB/d Gini & & -0.04771 & & & 56 \\
\hline & & & & 10.989 & 11.142 \\
\hline Final income inequality 2005 & 15233 & 46.74575 & 4.616776 & & \\
\hline d SWB/d labour mob. & & 11.05871 & & & \\
\hline
\end{tabular}

Notes: Summary statistics for the regression sample of Table 8 , columns 1 and 2 . Total marginal effects are calculated using the coefficient estimates.

62. The total marginal effects in Table 9 that relate to final income inequality and actual social mobility are almost indistinguishable for various values of the interacted variable (e.g. the total effect of income inequality varies between -0.049 and -0.046). In other words, taking account of the potential interaction does not decisively affect the calculation of the marginal effect, which is also reflected in the insignificance of the interaction term estimate in column 2 of Table $8 .{ }^{38}$

38. The total marginal effects for specifications that interact perceived social mobility with income inequality can easily be calculated (as shown above) as the subjective component of the interaction term takes on values of either 0 or 1 , being constructed as dichotomous variable. 
63. In sum, the interaction between market income inequality and actual social mobility is somewhat surprising. To illustrate, a decrease in market income inequality by the distance between its maximum and its minimum in our sample (about -15 points) would lower SWB by about $10 \%$ of a SWB category if social mobility were at the sample maximum, but increase SWB by about the same magnitude if social mobility were at the sample minimum. The implications of this finding will be discussed later.

\subsection{Perceived and actual social mobility: contrasting the evidence (Tables 7 and 8)}

\section{Interactions with income inequality}

64. The findings in Tables 7 and 8 are similar insofar as they both show pronounced interactions of actual and perceived social mobility with market income inequality only, while the coefficient on the interplay with the final income distribution is rarely independently significant (albeit it is jointly with the interacting variables). To some extent, one may conclude that government activities that redistribute market generated income through transfers and taxes disentangle social mobility (perceptions) effects from (final) income inequality effects for SWB.

\section{Direct effects of market versus those of final income inequality}

65. Tables 7 and 8 are somewhat inconclusive to whether people care more about pre- or final income inequality. The results in Table 7 suggest that it is rather final income distribution that matters to SWB, being in line with the conjecture that social comparisons ('keeping up with the Joneses') are based on actual consumption patterns. In contrast, using a different specification and in a smaller sample, Table 8 suggests that social comparisons occur mainly on basis of market income inequality. However, the estimates of Table A7 indicate that the effects of income inequality are somewhat sensitive to which countries are included in the sample, yielding statistically weak correlation for both market and final inequality. In sum, effects of income inequality per se appear highly sensitive to the countries included, adding to the problem that due to the high correlations among the aggregate factors in the small country sample statistical identification is hampered and final conclusions are difficult to draw.

\section{Direct effects of perceived social mobility}

66. The finding that perceived social mobility per se is not relevant for people's well-being is supported by all analyses of Tables 8, 7 and A7 likewise. In all models, the significance levels of its coefficients are considerably lower when its interaction with either type of income inequality is included in the model. The interaction of social mobility perceptions with inequality is positive - suggesting that the perception of equal opportunities in society mitigates (or overcompensates) the negative association of inequality with subjective well-being (Alesina et al., 2004). As the following discussion will show, the results for social mobility also hold when it is split into its single components 'confidence in education system', 'poverty due to laziness, not bad luck', and 'escape from poverty is possible', and when its effects are estimated for world sample.

\subsection{Single components of perceived social mobility}

67. It may be argued that the results for perceived social mobility are driven by the 'confidence in education system' component of the perceived social mobility measure. For this reason, Table 10 repeats the analysis of Table 7 replacing the composite measure of self-report social mobility with its single components. These two components include the social mobility perception reflected in the belief in 'escaping poverty is possible', on the one hand, and that 'poverty is caused through laziness, not through bad luck'. These two variables are identical to those that have been employed by Alesina et al. (2004) to contrast social mobility perceptions in the US to that in Western European countries. Notably, 
information on these two components are available for only three countries in our data, possibly affecting identification of effects.

\section{Empirical analysis: OECD countries}

68. Columns 1,2 and 3 of Table 10 show that subjective social mobility is positively associated with subjective well-being, irrespective of its definition. These effects are robust to the inclusion of measures of pre- and post-transfer income inequality (not reported). ${ }^{39}$ Due to the small sample, both coefficient estimates are insignificant. Low variation of income inequality at the country level is probably the cause for the insignificant coefficient on most of the interaction terms in columns 4 to 7 . Only the interactions of 'poverty due to laziness rather than luck' with the income inequality measures are significant - stronger for market income than for final income. In both cases, perceptions of social mobility mitigate the (potentially) well-being lowering effect of income inequality, while social perceptions per se are negatively associated with subjective well-being. Notably, the correlation between the interaction term and the social mobility perception is so close to 1 that these findings should be taken with a grain of salt.

\section{Empirical analysis: world sample}

69. To remedy this restriction, the same exercise has been carried out for a world sample obtained from the same World Values Survey data, matched with information provided by the World Bank on income inequality (see Table 11). The World Bank Gini coefficients do not differentiate between the type of income and data sources on which their calculations are based on. Definitions of social mobility perceptions that are tested include the 3-component one analogously to Table 7, the 2-component one as well as the two single-component ones used in Table 10; samples include either 38 or 8/9 countries. Controlling for country fixed effects and income inequality, each social mobility measure appears positively correlated with life satisfaction in the world (not reported). Again, living in a subjectively socially mobile society makes people happy. In these cross-sections, income inequality appears positively associated with subjective well-being.

70. Turning to the SWB effects of interest, namely the interplay between income inequality and subjective social mobility, for all variants of social mobility perceptions in columns 1 to 4 of Table 11 positive coefficient estimates on the interaction terms are observable, while social mobility perceptions per se often yield negative coefficients. The tests of joint significance at the bottom of the table suggest that due to the high correlations between perceived social mobility and the interaction terms standard errors are inflated. Columns 5 to 8 test specifications which omit the social mobility perceptions per se from the model, based on the observation that t-statistics for the interaction terms are relatively larger than that of the direct effects in the previous four models. The positive coefficient estimates of the interaction terms are now significant at the 5 percent level, indicating that social mobility perceptions enlarge the positive direct association between income inequality and individual SWB. The similarity of the interaction term coefficients across models (when per se perceptions are either included or excluded, e.g. column 1 versus column 5) suggest, again, that social mobility perceptions play a role for SWB only in their interplay with income inequality, but not directly.

\footnotetext{
39. Results are available on request.
} 
Table 10: Components of social mobility perceptions in OECD countries

\begin{tabular}{|c|c|c|c|c|c|c|c|c|c|}
\hline & 1 & 2 & 3 & 4 & 5 & 6 & 7 & 8 & 9 \\
\hline \multirow[t]{2}{*}{ Market (pre) Gini 2005} & & & & -0.006 & & -0.026 & & -0.034 & \\
\hline & & & & {$[0.26]$} & & {$[0.67]$} & & {$[1.40]$} & \\
\hline \multirow[t]{2}{*}{ Final (post) Gini 2005} & & & & & 0.012 & & 0.008 & & -0.028 \\
\hline & & & & & {$[0.29]$} & & {$[0.12]$} & & {$[0.57]$} \\
\hline Perc. soc. mob. 2 & $0.351^{* *}$ & & & 0.233 & 0.424 & & & & \\
\hline (laziness, poverty escape) & [19.29] & & & {$[0.98]$} & {$[2.45]$} & & & & \\
\hline \multirow[t]{2}{*}{ Perc. social mob. 2 * Gini pre/post } & & & & 0.004 & -0.002 & & & & \\
\hline & & & & {$[0.52]$} & {$[0.39]$} & & & & \\
\hline \multirow[t]{2}{*}{ Escaping poverty is possible } & & $0.286+$ & & & & -0.587 & 0.231 & & \\
\hline & & {$[2.97]$} & & & & {$[0.66]$} & {$[0.14]$} & & \\
\hline \multirow[t]{2}{*}{ Escape * Gini pre/post } & & & & & & 0.028 & 0.001 & & \\
\hline & & & & & & {$[1.05]$} & {$[0.03]$} & & \\
\hline \multirow[t]{2}{*}{ Poverty due to laziness, not bad luck } & & & $0.262+$ & & & & & $-0.807^{* *}$ & $-1.848+$ \\
\hline & & & {$[3.17]$} & & & & & [11.84] & [3.24] \\
\hline \multirow[t]{2}{*}{ Laziness * Gini pre/post } & & & & & & & & $0.035^{\star *}$ & $0.047+$ \\
\hline & & & & & & & & [16.88] & [3.49] \\
\hline \multirow[t]{2}{*}{ Constant } & $6.574^{* *}$ & $6.623^{*}$ & $6.761^{* *}$ & $6.683^{* *}$ & $5.928+$ & $7.341^{* *}$ & 6.137 & $7.743^{* *}$ & $7.942+$ \\
\hline & [9.98] & {$[8.74]$} & [10.35] & [68.89] & {$[4.08]$} & [14.30] & {$[2.46]$} & [25.28] & {$[4.28]$} \\
\hline Observations & 4082 & 4031 & 3445 & 4082 & 4082 & 4031 & 4031 & 3445 & 3445 \\
\hline R-squared & 0.1026 & 0.1003 & 0.1017 & 0.1023 & 0.1023 & 0.1000 & 0.0997 & 0.1019 & 0.1016 \\
\hline No of countries & 3 & 3 & 3 & 3 & 3 & 3 & 3 & 3 & 3 \\
\hline \multicolumn{10}{|l|}{ F-test (Gini, perc. soc. mob.) } \\
\hline \multicolumn{10}{|l|}{ p-value } \\
\hline $\begin{array}{l}\text { F-test (Gini, perc. soc. mob., Gini * perc. } \\
\text { soc. mob.) }\end{array}$ & & & & 0.5581 & 3.6106 & 0.2485 & 0.0107 & 80.4978 & 1030.594 \\
\hline $\mathrm{p}$-value & & & & 0.6418 & 0.2169 & 0.8009 & 0.9894 & 0.0123 & 0.001 \\
\hline
\end{tabular}

Notes: Weighted OLS regressions for 44'000 persons from 30 OECD countries. Dependent variable: Life satisfaction measured on a 10-point scale. Standard errors corrected for within-country correlation. '**', '*', '+' denote significances at the 1,5 and 10 percent levels, respectively. All models include age, gender, occupational status, civil status, attitudes, social capital as described in Table A2 of the Appendix. 
Table 11: Components of social mobility perceptions: world sample

\begin{tabular}{|c|c|c|c|c|c|c|c|c|}
\hline & 1 & 2 & 3 & 4 & 5 & 6 & 7 & 8 \\
\hline \multirow[t]{2}{*}{ Perc. soc. mob. } & 0.006 & & & & & & & \\
\hline & [0.03] & & & & & & & \\
\hline \multirow[t]{2}{*}{ Perc. soc. mob. * Gini } & 0.008 & & & & $0.009^{* *}$ & & & \\
\hline & {$[1.26]$} & & & & {$[6.34]$} & & & \\
\hline \multirow[t]{2}{*}{ Perc. soc. mob. 2} & & -0.101 & & & & & & \\
\hline & & {$[0.17]$} & & & & & & \\
\hline \multirow[t]{2}{*}{ (Perc. soc. mob. $2{ }^{*}$ Gini } & & 0.009 & & & & $0.007^{*}$ & & \\
\hline & & [0.69] & & & & [3.02] & & \\
\hline \multirow[t]{2}{*}{ Poverty is due to laziness } & & & -0.263 & & & & & \\
\hline & & & {$[0.70]$} & & & & & \\
\hline \multirow[t]{2}{*}{ Laziness * Gini } & & & 0.012 & & & & $0.006^{* *}$ & \\
\hline & & & [1.35] & & & & [3.57] & \\
\hline \multirow[t]{2}{*}{ Escaping poverty is possible } & & & & -0.042 & & & & \\
\hline & & & & {$[0.07]$} & & & & \\
\hline \multirow[t]{2}{*}{ Escape * Gini } & & & & 0.008 & & & & $0.007^{*}$ \\
\hline & & & & {$[0.55]$} & & & & {$[2.46]$} \\
\hline \multirow[t]{2}{*}{ Gini } & $0.009^{* *}$ & $0.031+$ & $0.030^{*}$ & $0.033+$ & $0.009^{* *}$ & $0.032^{* *}$ & $0.032^{* *}$ & $0.034^{* *}$ \\
\hline & {$[2.84]$} & {$[2.12]$} & {$[2.87]$} & [2.28] & {$[7.27]$} & [4.96] & {$[4.58]$} & {$[4.57]$} \\
\hline \multirow[t]{2}{*}{ Constant } & $6.862^{* *}$ & $5.540^{* *}$ & $5.650^{* *}$ & $5.667^{* *}$ & $6.866^{* *}$ & $5.465^{* *}$ & $5.517^{* *}$ & $5.638^{* *}$ \\
\hline & [26.92] & [5.83] & [6.98] & [5.73] & [30.48] & {$[8.97]$} & {$[8.06]$} & [8.26] \\
\hline Observations & 40499 & 11419 & 10593 & 10307 & 40499 & 11419 & 10593 & 10307 \\
\hline R-squared & 0.2881 & 0.215 & 0.2123 & 0.231 & 0.2881 & 0.215 & 0.2122 & 0.231 \\
\hline No of countries & 38 & 9 & 9 & 8 & 38 & 9 & 9 & 8 \\
\hline country FE & yes & yes & yes & yes & yes & yes & yes & yes \\
\hline $\begin{array}{l}\text { F-test perc. soc. mob, perc. soc. mob. }{ }^{*} \\
\text { Gini }\end{array}$ & 28.8117 & 6.3352 & 7.4652 & 4.3455 & & & & \\
\hline p-value & 0.000 & 0.0224 & 0.0148 & 0.0593 & & & & \\
\hline
\end{tabular}

Notes: Weighted OLS regressions for 110'000 persons from 70 countries. Dependent variable: Life satisfaction measured on a 10-point scale. Standard errors corrected for withincountry correlation. ' $* *$ ', '*', ' '+' denote significances at the 1,5 and 10 percent levels, respectively. All models include age, gender, occupational status, civil status, attitudes, social capital as described in Table A2 of the Appendix. 


\section{Summary on the interplay between inequality and social mobility}

71. Taken all together, Tables 6 to 10 link nicely to the conjectures made by Alesina et al. (2004) about the interactions between income inequality and perceived social mobility:

72. A wider market income distribution, has a negative effect on subjective well-being. However, its interactions with perceived social mobility are always significant and positive. Thus, the negative effects of market-generated income dispersion can be mitigated by higher perceived social mobility. With respect to the interplay between actual social mobility and market generated income inequality, the opposite is observed: less social mobility appears to mitigate the negative association of inequality with SWB.

73. The next section discusses further, partly more speculative conclusions that could be drawn from the preceding empirical analyses.

\section{Further discussion of results}

74. The analyses show that there is a positive correlation between actual or perceived social mobility and subjective well-being, and that providing equal opportunities in terms of educational attainment does not depend on the wealth of a country (see Table 3 ).

\section{Political ideology and social mobility}

75. Only politically conservative persons appear to prefer intergenerational mobility in educational attainment or earnings mobility in the labour market, while leftist oriented persons appear indifferent (Table 4). Leftist oriented persons may be somewhat indifferent toward the extent of social mobility (that affects market-generated income) because they have reasons to believe that redistributive measures are undertaken by governments to correct unfair market outcomes. On the other hand, conservative persons appear to appreciate social mobility. Corneo and Gruener (2002), and Alesina and LaFerrara (2005) show that less social mobility and more unequal opportunities lead to a greater population demand for corrective income redistribution and equalization of consumption patterns through public goods which would be contrary to conservative persons' preferences.

76. Table 5 reveals that perceived social mobility does not correlate with actual social mobility measured by the elasticity of one's own earnings to one's parents' earnings. While perceived social mobility mediates the effects of social mobility in terms of educational attainment, it does not so for social mobility in the labour market. This finding may be explained by the fact that people form their perceptions of actual social mobility based on equal opportunities in education, being unable to observe social mobility in the labour market, given that e.g. wages are often not transparent.

77. Tables 6 and 7 suggest that final income distribution is negatively associated with subjective well-being, but not market-generated income distribution. This finding may be indirect evidence that social comparisons are based on differences in actual consumption, which is determined by disposable income, rather than market income. Indeed, the relatively low correlation between market and final income inequality of about 0.5 supports the view of differential effects.

\section{Perceived social mobility and income inequality}

78. Tables 7 and 8 show that only market income inequality has a positive interplay with social mobility perceptions, while the interplay of final income inequality is statistically weak. It has been 
concluded that subjective social mobility makes market income inequality more tolerable or may even lead to it being viewed positively. That the interplay of social mobility perceptions is stronger with market income inequality may have its cause in the definition of the mobility perception variable: it relates social mobility and poverty to effort/laziness and education. Market incomes, however, are supposedly determined by one's human capital accumulation and effort, which applies less to income after correcting taxation and social transfers have been applied (the correlation between market and final income inequality is relatively low). The same analyses also show that viewing oneself in a socially mobile society is only associated with SWB through its interplay with income inequality.

\section{Actual social mobility and income inequality}

79. Tables 8 and 9 illustrate the interplay between actual social mobility and market income inequality, which yields results that contradict everyday intuition: The interplay between actual social mobility in the labour market and market-generated income inequality yields a negative sign. For societies in which income inequality reduces SWB, low social mobility mitigates its SWB lowering effect, while high social mobility enlarges it. Potentially, high actual social mobility increases people's impression of forgone earnings opportunities, triggering feelings of disappointment or envy, so that negative social comparisons effects caused by an unequal income distribution are enlarged. ${ }^{40}$ Thus, the higher social mobility in the labour market, the larger the SWB lowering effect of market-generated income inequality is. In contrast, low actual social mobility makes it easier (in a fatalistic perspective) to accept existing socio-economic cleavages.

80. The interpretation of the interaction effect of 'actual social mobility' is opposite to the interpretation of the positive interaction between 'perceived social mobility' and income inequality, which rests on fairness perception and income expectation arguments. Possibly, perceived social mobility has a strong future-oriented element, also reflecting people's overly optimistic view on their own socioeconomic improvement, while actual mobility relates to the current, fixed status quo in society. Thus, actual social mobility may enlarge the SWB lowering effect of income inequality as people's impression of forgone income opportunities may aggravate the negative impact of social comparison effects. In contrast, perceived social mobility mitigates the SWB lowering effects of income inequality as people are more inclined to interpret the existing income differences as future opportunities. Thus, for an OECD country with a high degree of income inequality, it may be better to have low actual social mobility compared to having high social mobility. As Table 1 shows, in the US and in the UK, income inequality is higher and actual (not perceived) social mobility in the labour market is lower compared to Western Continental Europe - the better combination in the light of these results.

\section{Conclusion}

81. The Subjective Well-being effects of social mobility in society have been largely neglected in happiness research. Empirical evidence on the SWB effects of living in a socially mobile society have been only indirect, through comparisons of relative income and inequality effects across countries (e.g. Alesina et al., 2004; Senik, 2008).

82. That social mobility increases SWB a priori should not be taken for granted. A closed society may be linked to having a stable socio-economic environment and income security, and may be preferred over the insecure state of 'social mobility' particularly if the population is largely risk averse or has a taste for an egalitarian society (similarly, see Corneo and Gruener, 2002). The work by Senik (2008) suggests

40. For literature on social comparison effects on happiness, see footnote 2. 
that income inequality was perceived as positive in the ex-communist countries during their societal transition phases, compared to the established Western European societies. When lauding the advantages of social mobility, one should not forget that mobility is not only upwards, but equally downwards. Empirical research on the SWB effects of individual downward mobility is still lacking, which may exceed that of upward mobility due to 'loss aversion' and feelings of 'relative deprivation' (see e.g. Fischer and Torgler, 2008).

83. A fine distinction between perceived and actual social mobility should be made. Possibly due to subjective misperceptions, both are not closely correlated with each other: In a society that is perceived as mobile, due to optimism bias most persons predict for themselves a positive income trajectory, even though their actual social positions remain unaltered or may even worsen over time. In contrast, actual social mobility may be linked to actual income comparisons that occur at the present societal state. In this study, both objective measures as well as subjective measure of societal social mobility are tested for their SWB effects.

84. Using data from the combined $3^{\text {rd }}$ and $4^{\text {th }}$ World Values Survey on 30 OECD countries, we find that actual social mobility in society, measured by intergenerational earnings elasticity and intergenerational dependence of student attainment, is positively correlated with SWB, both for the wellbeing of society as a whole but also for individuals' SWB. Most importantly, the positive social mobility effects are independent of that of national wealth and economic development. Approximating perceived social mobility with a measure mainly building on having confidence in the education system, we find perceived social mobility to positively affect SWB, with further analysis suggesting that its effect is entirely mediated through its interplay with income inequality.

85. As conjectured by Alesina et al. (2004), a high degree of perceived social mobility appears to mitigate or even reverse the negative SWB impact of market income inequality, even when controlling for actual social mobility (and its interaction with inequality). In contrast, in countries with a high degree of actual social mobility in the labour market we identify an overall negative impact of market income inequality on SWB, while for countries with social immobility the effects of inequality are even positive. It is conjectured that well-being lowering social comparisons effects, that are triggered by an unequal distribution of income, are aggravated through feelings of forgone earnings opportunities and regret (of having made the wrong choices), reflected by actual social mobility. These findings mirror exactly the negative income inequality effect for SWB in Western European countries identified by Alesina et al. (2004), and the rather insignificant effects of income inequality in the USA, a country with a relatively low actual social mobility but high income inequality. Negative associations between inequality and SWB are observable both for inequality in disposable income as well as market-generated income, leaving open whether social comparison effects are based on actual consumption only.

86. This paper shows that equality in educational opportunities and earnings mobility in the labour market are two rather distinct facets of social mobility. It also reveals that social mobility perceptions and actual social mobility do not necessarily move in parallel with each other. This becomes particularly evident in the assessment of their interplay with income inequality in society. Obviously, perceptions may reflect what people hope will happen in the future, so that they entail a strong aspiration component, while actual mobility relates to the current situation, the status quo. To increase welfare, countries with high actual social mobility should aim at achieving a narrow income distribution. 


\section{REFERENCES}

Alesina, A. and La Ferrara, E., (2005), Preferences for redistribution in the land of opportunities, Journal of Public Economics 89, 897-931.

Alesina, A., R. Di Tella and R. MacCulloch (2004), Inequality and happiness: are Europeans and Americans different?, Journal of Public Economics 88, 2009-2042.

Alesina, A. and G.-M. Angeletos (2003), Fairness and Redistribution: U.S. versus Europe, National Bureau of Economic Research, NBER Working Papers 9502.

Alesina, A. and E. La Ferrara (2002), Who Trusts Others?, Journal of Public Economics 85, 207-234.

Alesina, A., E. Glaeser, and B. Sacerdote, (2001), Why Doesn't The US Have a European-Style Welfare State?, Harvard Institute of Economic Research Working Papers 1933,

Becker, G. S. and N. Tomes (1979). "An Equilibrium Theory of the Distribution of Income and Intergenerational Mobility.” Journal of Political Economy 87, 1153-89.

Berggren, N. and H. Jordahl (2006), Free to Trust: Economic Freedom and Social Capital, Kyklos 59, 141169

Bjørnskov, C., A. Dreher, and J.A.V. Fischer (2008a), On Decentralization and Life Satisfaction, Economics Letters 99, 147-151.

Bjørnskov, C., A. Dreher, and \& J.A.V. Fischer (2008b), Cross-country determinants of life satisfaction: exploring different determinants across groups in society, Social Choice and Welfare 30, 119-173.

Bjørnskov, C., A. Dreher, and \& J.A.V. Fischer (2008c), Formal Institutions and Subjective Well-Being: Revisiting the Cross-Country Evidence, Working Paper Series in Economics and Finance 699, Stockholm School of Economics

Bjørnskov, C., A. Dreher, J.A.V. Fischer and J. Schnellenbach (2008), On the relation between inequality and happiness - do fairness perceptions matter ?, mimeo, Stockholm School of Economics.

Bjørnskov, C., A. Dreher, and J.A.V. Fischer (2007), The bigger the better? Evidence of the effect of government size on life satisfaction around the world, Public Choice 130, 267-292.

Bjørnskov, C. (2007), Determinants of generalized trust: A cross-country comparison, Public Choice 130, $1-21$.

Borjas, G.J. (1992), Ethnic Capital and Intergenerational Mobility, Quarterly Journal of Economics, 107, 123-50.

Breen, R., ed., (2004), Social Mobility in Europe, Oxford: Oxford University Press 
Corak, M. (2006), Do Poor Children Become Poor Adults? Lessons from a Cross Country Comparison of Generational Earnings Mobility, Research on Economic Inequality 13, 143-188.

Corneo, G. and H.P. Gruener (2002), Individual preferences for political redistribution, Journal of Public Economics 83, 83-107.

Dolan, P., T. Peasgood, and M. White (2008), Do we really know what makes us happy ? A review of the economic literature on the factors with subjective well-being, Journal of Economic Psychology 29, 94-122.

Dorn, D. Justina AV Fischer, G. Kirchgässner, and A. Sousa-Poza, Is It Culture or Democracy? The Impact of Democracy and Culture on Happiness, Social Indicators Research 82, 505-526, 2007.

D'Addio, A. C. (2007), "Intergenerational Transmission of Disadvantage: Mobility or Immobility Across Generations?", OECD Social Employment and Migration Working Papers, No. 52.

Encyclopaedia Britannica (2009), “feudalism”, In Encyclopædia Britannica. Retrieved June 17, 2009, from Encyclopædia Britannica Online: http://www.britannica.com/EBchecked/topic/205583/feudalism

Fehr, E. and K.M. Schmidt (1999), A Theory Of Fairness, Competition, and Cooperation, Quarterly Journal of Economics 114, 817-868

Ferrer-i-Carbonell, A. (2005), Income and well-being: an empirical analysis of the comparison income effect, Journal of Public Economics 89, 997-1019.

Ferrer-i-Carbonell, A. and P. Frijters (2004), How Important is Methodology for the estimates of the determinants of Happiness? The Economic Journal 114, 641-659.

Fischer, J.A.V. and B. Torgler (2008), Social Capital and Relative Income Concerns: Evidence from 26 Countries, Thurgauer Wirtschaftsinstitut, Universität Konstanz, TWI Research Paper Series 38.

Fong, C. (2001), Social preferences, self-interest and the demand for redistribution, Journal of Public Economics 82, 225-246.

Helliwell, J.F. and H. Huang (2007), How's Your Government? International Evidence Linking Good Government and Well-Being, British Journal of Political Science 38, 595-619.

Helliwell, John F. (2001), Social Capital, the Economy and Well-Being, in: K. Banting, A. Sharpe and F. St-Hilaire (eds.), The Review of Economic Performance and Social Progress. The Longest Decade: Canada in the 1990s. Montreal: Institute for Research on Public Policy: 43-60.

Jordahl, H. (2007), Inequality and Trust, IFN Working Paper No. 715.

Kingdon, G.G. and J. Knight (2007), Community, comparisons and subjective well-being in a divided society, Journal of Economic Behavior \& Organization 64, 69-90

OECD (2004), Learning for Tomorrow's World: First Results from PISA 2003, Paris: OECD 2004.

OECD (2007), Society at a Glance: OECD Social Indicators 2006, Paris: OECD 2007. 
OECD (2008), Growing Unequal? Income Distribution and Poverty in OECD Countries, Paris: OECD 2008.

Piketty, T. (1995), Social Mobility and Redistributive Politics, Quarterly Journal of Economics 110, 55184.

Robinson, W.S. (1950), Ecological correlations and the behavior of individuals, American Sociological Review 30, 351-357

Roemer, J.E. (2002), Equality of opportunity: A progress report, Social Choice and Welfare 19, 455-471.

Senik, C. (2008), Ambition and Jealousy: Income Interactions in the 'Old' Europe versus the 'New' Europe and the United States, Economica 75, 495-513.

Tortia, E.C. (2008), Worker Well-Being and perceived fairness: Survey-based findings from Italy, Journal of Socio-Economics 37, 2080-2094.

Vallet LA. (2004), Change in intergenerational class mobility in France from the 1970s to the 1990s and its explanation: an analysis following the CASMIN approach, Cahiers du Lasmas 01-2. Reprinted in Breen (2004), 115-48.

Uslaner, E.M. (2008), Where You Stand Depends Upon Where Your Grandparents Sat: The Inheritability of Generalized Trust, Public Opinion Quarterly 72, 725-740. 
DELSA/ELSA/WD/SEM(2009)21

\section{APPENDIX}

Table A1: Income inequality in OECD countries

\begin{tabular}{|c|c|c|c|c|}
\hline Country & $\begin{array}{c}\text { Market Gini } \\
\text { coefficients of around } \\
2000 \\
\end{array}$ & $\begin{array}{c}\text { Market Gini } \\
\text { coefficients of } 2005\end{array}$ & $\begin{array}{c}\text { Final Gini } \\
\text { coefficients of } 2000\end{array}$ & $\begin{array}{c}\text { Final Gini } \\
\text { coefficients of } 2005\end{array}$ \\
\hline Australia & 32 & 30 & 48 & 46 \\
\hline Austria & 25 & 27 & & 43 \\
\hline Belgium & 29 & 27 & 46 & 49 \\
\hline Canada & 30 & 32 & 42 & 44 \\
\hline Switzerland & 28 & 28 & 35 & 35 \\
\hline Czech Republic & 26 & 27 & 47 & 47 \\
\hline Germany & 27 & 30 & 48 & 51 \\
\hline Denmark & 23 & 23 & 41 & 42 \\
\hline Spain & 34 & 32 & & \\
\hline Finland & 26 & 27 & 39 & 39 \\
\hline France & 28 & 28 & 50 & 48 \\
\hline United Kingdom & 37 & 34 & 48 & 46 \\
\hline Greece & 34 & 32 & & \\
\hline Hungary & 29 & 29 & & \\
\hline Ireland & 30 & 33 & 43 & 42 \\
\hline Iceland & & 28 & & 37 \\
\hline Italy & 34 & 35 & 52 & 56 \\
\hline Japan & 34 & 32 & 43 & 44 \\
\hline Korea & & 31 & & 34 \\
\hline Luxembourg & 26 & 26 & & 45 \\
\hline Mexico & 51 & 47 & & \\
\hline Netherlands & 28 & 27 & 42 & 42 \\
\hline Norway & 26 & 28 & 41 & 43 \\
\hline New Zealand & 34 & 34 & 48 & 47 \\
\hline Poland & 32 & 37 & & 57 \\
\hline Portugal & 36 & 38 & 48 & 54 \\
\hline Slovak Republic & & 27 & & 46 \\
\hline Sweden & 24 & 23 & 45 & 43 \\
\hline Turkey & & 43 & & \\
\hline United States & 36 & 38 & 45 & 46 \\
\hline
\end{tabular}

Notes: Market Gini coefficients are based on gross income data. Final Gini coefficients are based on income after taxes, transfers and social security contributions. All information is obtained from OECD (2008). 
Table A2: Descriptive statistics of individual-specific factors

\begin{tabular}{|c|c|c|c|c|c|c|}
\hline Variable & Obs & Mean & Std. Dev. & Min & Max & OLS \\
\hline Life Satisfaction & 34229 & 7.11 & 2.28 & 1 & 10 & \\
\hline male & 34229 & 0.48 & 0.50 & 0 & 1 & $-0.107^{\star *}$ \\
\hline Age & 34229 & 43.95 & 16.65 & 15 & 98 & $-0.069^{* *}$ \\
\hline Age squ1red/100 & 34229 & 22.09 & 16.05 & 2.25 & 96.04 & $0.071^{* *}$ \\
\hline Education category 1 (low) & \multicolumn{5}{|c|}{ Reference category } & \\
\hline Education category 2 & 34229 & 0.20 & 0.40 & 0 & 1 & 0.137 \\
\hline Education category 3 & 34229 & 0.13 & 0.34 & 0 & 1 & 0.223 \\
\hline Education category 4 & 34229 & 0.12 & 0.33 & 0 & 1 & 0.194 \\
\hline Education category 5 & 34229 & 0.09 & 0.29 & 0 & 1 & 0.139 \\
\hline Education category 6 & 34229 & 0.17 & 0.38 & 0 & 1 & 0.228 \\
\hline Education category 7 & 34229 & 0.10 & 0.30 & 0 & 1 & 0.124 \\
\hline Education category 8 (high) & 34229 & 0.12 & 0.32 & 0 & 1 & 0.227 \\
\hline Income category 1 (low) & \multicolumn{5}{|c|}{ Reference category } & \\
\hline Income category 2 & 34229 & 0.14 & 0.34 & 0 & 1 & $0.171^{*}$ \\
\hline Income category 3 & 34229 & 0.14 & 0.35 & 0 & 1 & $0.384^{* *}$ \\
\hline Income category 4 & 34229 & 0.14 & 0.35 & 0 & 1 & $0.571^{* *}$ \\
\hline Income category 5 & 34229 & 0.13 & 0.34 & 0 & 1 & $0.711^{* *}$ \\
\hline Income category 6 & 34229 & 0.10 & 0.30 & 0 & 1 & $0.766^{\star *}$ \\
\hline Income category 7 & 34229 & 0.09 & 0.29 & 0 & 1 & $0.882^{* *}$ \\
\hline Income category 8 & 34229 & 0.07 & 0.25 & 0 & 1 & $0.818^{* *}$ \\
\hline Income category 9 & 34229 & 0.05 & 0.23 & 0 & 1 & $0.851^{* *}$ \\
\hline Income category 10 (high) & 34229 & 0.05 & 0.23 & 0 & 1 & $0.995^{\star *}$ \\
\hline Divorced & \multicolumn{5}{|c|}{ Reference category } & \\
\hline Single & 34229 & 0.23 & 0.42 & 0 & 1 & 0.044 \\
\hline Married/cohabiting & 34229 & 0.62 & 0.49 & 0 & 1 & $0.423^{* *}$ \\
\hline Separated & 34229 & 0.02 & 0.13 & 0 & 1 & $-0.355^{* *}$ \\
\hline Widowed & 34229 & 0.07 & 0.26 & 0 & 1 & -0.115 \\
\hline No children & \multicolumn{5}{|c|}{ Reference category } & \\
\hline Has had 1 child & 34229 & 0.15 & 0.35 & 0 & 1 & 0.046 \\
\hline Has had 2 children & 34229 & 0.30 & 0.46 & 0 & 1 & $0.101+$ \\
\hline Has had $>=3$ children & 34229 & 0.28 & 0.45 & 0 & 1 & $0.134+$ \\
\hline Full time employed & \multicolumn{5}{|c|}{ Reference category } & \\
\hline Self-employed & 34229 & 0.07 & 0.26 & 0 & 1 & -0.089 \\
\hline Part-time employed & 34229 & 0.08 & 0.27 & 0 & 1 & -0.087 \\
\hline Housewife & 34229 & 0.13 & 0.34 & 0 & 1 & 0.048 \\
\hline Retired & 34229 & 0.18 & 0.38 & 0 & 1 & -0.048 \\
\hline Other occupation & 34229 & 0.02 & 0.14 & 0 & 1 & $-0.247^{*}$ \\
\hline Student & 34229 & 0.05 & 0.21 & 0 & 1 & 0.021 \\
\hline Unemployed & 34229 & 0.06 & 0.23 & 0 & 1 & $-0.848^{* *}$ \\
\hline Centrist-conservative & 34229 & 0.37 & 0.48 & 0 & 1 & $0.196^{* *}$ \\
\hline Centrist-left & \multicolumn{5}{|c|}{ Reference category } & \\
\hline No political ideology & 34229 & 0.13 & 0.34 & 0 & 1 & 0.046 \\
\hline Belief in superior being & 34229 & 0.72 & 0.45 & 0 & 1 & $0.061+$ \\
\hline
\end{tabular}


Table A2: Descriptive statistics of individual-specific factors (cont.)

\begin{tabular}{|c|c|c|c|c|c|c|}
\hline Buddhist & 34229 & 0.02 & 0.14 & 0 & 1 & 0.011 \\
\hline Muslim & 34229 & 0.12 & 0.32 & 0 & 1 & $-0.379+$ \\
\hline Catholic & 34229 & 0.35 & 0.48 & 0 & 1 & -0.052 \\
\hline No religion & \multicolumn{5}{|c|}{ Reference category } & \\
\hline Protestant & 34229 & 0.21 & 0.41 & 0 & 1 & 0.055 \\
\hline Orthodox & 34229 & 0.03 & 0.16 & 0 & 1 & -0.046 \\
\hline Other Christian religion & 34229 & 0.01 & 0.10 & 0 & 1 & 0.124 \\
\hline Other religion & 34229 & 0.02 & 0.13 & 0 & 1 & -0.023 \\
\hline Jewish & 34229 & 0.00 & 0.05 & 0 & 1 & -0.354 \\
\hline Service attendance 1(>weekly) & 34229 & 0.07 & 0.26 & 0 & 1 & $0.368^{* *}$ \\
\hline Service attendance 2 & 34229 & 0.17 & 0.38 & 0 & 1 & $0.196^{*}$ \\
\hline Service attendance 3 & 34229 & 0.09 & 0.29 & 0 & 1 & 0.100 \\
\hline Service attendance 4 & 34229 & 0.15 & 0.35 & 0 & 1 & $0.145^{\star *}$ \\
\hline Service attendance 5 & 34229 & 0.03 & 0.18 & 0 & 1 & 0.106 \\
\hline Service attendance 6 & 34229 & 0.08 & 0.27 & 0 & 1 & 0.037 \\
\hline Service attendance 7 & 34229 & 0.09 & 0.28 & 0 & 1 & 0.037 \\
\hline Service attendance 8 (never) & \multicolumn{5}{|c|}{ Reference category } & \\
\hline Friends are important & 34229 & 0.92 & 0.27 & 0 & 1 & $0.339^{* *}$ \\
\hline Active membership & 34229 & 0.30 & 0.46 & 0 & 1 & $0.239^{* *}$ \\
\hline Has confidence in parliament & 34229 & 0.36 & 0.48 & 0 & 1 & $0.242^{* *}$ \\
\hline Has trust in peers & 34229 & 0.33 & 0.47 & 0 & 1 & $0.296 * *$ \\
\hline \multicolumn{7}{|c|}{ Analysis by political ideology } \\
\hline Leftist & 34229 & 0.23 & 0.42 & 0 & 1 & \\
\hline Conservative & 34229 & 0.29 & 0.45 & 0 & 1 & \\
\hline \multicolumn{7}{|c|}{ Social mobility perceptions and its components } \\
\hline $\begin{array}{l}\text { Perceived social mobility } \\
\text { (all } 3 \text { components) }\end{array}$ & 23009 & 0.70 & 0.46 & 0 & 1 & \\
\hline $\begin{array}{l}\text { Perceived social mobility } 2 \\
\text { (components } 1 \text { and 2) }\end{array}$ & 2700 & 0.68 & 0.47 & 0 & 1 & \\
\hline Component 1: Confidence in education & 20309 & 0.70 & 0.46 & 0 & 1 & \\
\hline Component 2: Laziness & 2219 & 0.50 & 0.50 & 0 & 1 & \\
\hline Component 3: Escape poverty & 2664 & 0.61 & 0.49 & 0 & 1 & \\
\hline
\end{tabular}

Notes: Last column reports coefficient estimates with individual-level determinants only and country fixed effects. Dependent variable: life satisfaction measured on 10-point scale. '***', '**', '+' denote significances at the 1, 5 and 10 percent levels, respectively. Robust t-statistics obtained through clustering by country reported in brackets. 
Table A3: The role of social trust

\begin{tabular}{|c|c|c|c|c|c|c|}
\hline & 1 & 2 & 3 & 4 & 5 & 6 \\
\hline \multirow[t]{2}{*}{ Labour market mobility } & 24.442 & $60.961^{* *}$ & & & & \\
\hline & {$[1.28]$} & [3.74] & & & & \\
\hline \multirow[t]{2}{*}{ Educational mobility (father) } & & & $0.252+$ & 0.200 & & \\
\hline & & & {$[1.95]$} & {$[1.27]$} & & \\
\hline \multirow[t]{2}{*}{ Educational mobility (mother) } & & & & & $0.325^{*}$ & $0.327^{*}$ \\
\hline & & & & & {$[2.65]$} & [2.53] \\
\hline \multirow[t]{2}{*}{$\log (\mathrm{NNI})$} & -17.650 & 2.525 & 4.669 & $13.582^{* *}$ & 6.200 & $13.446^{* *}$ \\
\hline & {$[1.06]$} & {$[0.17]$} & {$[1.01]$} & [3.14] & {$[1.61]$} & [4.18] \\
\hline \multirow[t]{2}{*}{ Social trust in the population } & $0.528^{*}$ & & $0.573^{* *}$ & & $0.504^{* *}$ & \\
\hline & [2.43] & & {$[3.16]$} & & [3.01] & \\
\hline \multirow[t]{2}{*}{ Constant } & 220.586 & 52.166 & -4.81 & -72.32 & -16.475 & $-68.743^{*}$ \\
\hline & {$[1.37]$} & {$[0.35]$} & {$[0.11]$} & {$[1.58]$} & {$[0.47]$} & [2.06] \\
\hline Observations & 12 & 12 & 29 & 29 & 29 & 29 \\
\hline Adjusted R-squared & 0.6469 & 0.5169 & 0.5375 & 0.3868 & 0.5624 & 0.446 \\
\hline F-test (social mobility, social trust) & $20.91^{* *}$ & & $5.91^{* *}$ & & $7.76^{\star \star}$ & \\
\hline$p$-value & 0.0007 & & 0.0079 & & 0.0024 & \\
\hline
\end{tabular}

Notes: Dependent variable: Subjective Well-Being measured at the country level. Robust regressions for a sample of 30 OECD countries. 'Labour market mobility' is derived from intergenerational earnings elasticity, while 'educational mobility (mother/father)' is measured in terms of maternal/paternal education-dependence. Higher values indicate more social mobility. ' ‘**’, '‘*', '+'denote significances at the 1, 5 and 10 percent levels, respectively. T-statistics are reported in brackets. 
DELSA/ELSA/WD/SEM(2009)21

Table A4: Income inequality and life satisfaction in OECD countries: subsample

\begin{tabular}{|c|c|c|c|c|}
\hline & 1 & 2 & 3 & 4 \\
\hline \multirow[t]{2}{*}{ Market Gini 2000} & -0.017 & & & \\
\hline & {$[1.40]$} & & & \\
\hline \multirow[t]{2}{*}{ Final Gini 2000} & & $-0.045^{\star *}$ & & \\
\hline & & [3.25] & & \\
\hline \multirow[t]{2}{*}{ Market Gini 2005} & & & -0.015 & \\
\hline & & & {$[1.00]$} & \\
\hline \multirow[t]{2}{*}{ Final Gini 2005} & & & & $-0.030^{*}$ \\
\hline & & & & [2.99] \\
\hline Other micro controls & yes & yes & Yes & yes \\
\hline \multirow[t]{2}{*}{$\log (\mathrm{NNI})$} & -0.06 & -0.721 & 0.039 & -0.492 \\
\hline & {$[0.14]$} & {$[1.47]$} & {$[0.09]$} & {$[1.26]$} \\
\hline \multirow[t]{2}{*}{ Constant } & $8.210+$ & $16.577^{*}$ & 7.112 & $13.557^{* *}$ \\
\hline & {$[1.87]$} & [3.12] & [1.57] & [3.31] \\
\hline Observations & 17483 & 15233 & 17483 & 15233 \\
\hline R-squared & 0.1003 & 0.1064 & 0.0998 & 0.1042 \\
\hline No of countries & 12 & 11 & 12 & 11 \\
\hline
\end{tabular}

Notes: Weighted OLS regressions for 44'000 persons from 30 OECD countries. Dependent variable: Life satisfaction measured on a 10-point scale. Standard errors corrected for within-country correlation. '**', '*', ' + ' denote significances at the 1,5 and 10 percent levels, respectively. Estimations are for a subsample for which the labour market mobility variable is available. 'Other micro controls' include age, age squared, gender, education, occupational status, marital status, social capital, and attitudes. See table A2 of the Appendix. 
DELSA/ELSA/WD/SEM(2009)21

Table A5: Social mobility perceptions do not approximate actual social mobility

\begin{tabular}{|c|c|c|c|}
\hline & 1 & 2 & 3 \\
\hline Perceived social mobility 2 & $0.332^{*}$ & $0.348^{* *}$ & $0.355^{\star *}$ \\
\hline (laziness, poverty escape) & [25.43] & {$[15.34]$} & [17.93] \\
\hline \multirow[t]{2}{*}{ Labour market mobility } & 26.11 & & \\
\hline & [4.35] & & \\
\hline \multirow[t]{2}{*}{ Educational mobility (mother) } & & -0.004 & \\
\hline & & {$[1.15]$} & \\
\hline \multirow[t]{2}{*}{ Educational mobility (father) } & & & -0.007 \\
\hline & & & {$[0.64]$} \\
\hline Other micro controls & yes & Yes & yes \\
\hline \multirow[t]{2}{*}{ Constant } & $11.329^{*}$ & $6.415^{*}$ & $6.268^{* *}$ \\
\hline & [18.04] & {$[8.79]$} & [11.49] \\
\hline Observations & 3057 & 4082 & 4082 \\
\hline R-squared & 0.1108 & 0.1024 & 0.1025 \\
\hline No of countries & 2 & 3 & 3 \\
\hline
\end{tabular}

Notes: Weighted OLS regressions for 44'000 persons from 30 OECD countries. Dependent variable: Life satisfaction measured on a 10-point scale. 'Labour market mobility' is derived from intergenerational earnings elasticity, while 'educational mobility

(mother/father)' is measured in terms of maternal/paternal education-dependence. Higher values indicate more social mobility.

Standard errors corrected for within-country correlation. '**', '*', '+' denote significances at the 1,5 and 10 percent levels, respectively.

'Other micro controls' include age, age squared, gender, education, occupational status, marital status, social capital, and attitudes.

See table A2 of the Appendix. 
DELSA/ELSA/WD/SEM(2009)21

Table A6: Perceived social mobility: single components

\begin{tabular}{|c|c|c|c|c|c|c|}
\hline & 1 & 2 & 3 & 4 & 5 & 6 \\
\hline \multirow[t]{2}{*}{ Perceived social mobility 2} & $0.351^{* *}$ & & & $0.452^{* *}$ & & \\
\hline & [19.29] & & & [205.58] & & \\
\hline \multirow[t]{2}{*}{ Escaping poverty is possible } & & $0.286+$ & & & $0.392+$ & \\
\hline & & {$[2.97]$} & & & [4.16] & \\
\hline \multirow[t]{2}{*}{ Poverty due to laziness, not bad luck } & & & $0.262+$ & & & $0.337^{\star}$ \\
\hline & & & [3.17] & & & {$[6.68]$} \\
\hline Other micro controls & yes & yes & yes & yes & yes & yes \\
\hline \multirow[t]{2}{*}{ Constant } & $6.574^{* *}$ & $6.623^{*}$ & $6.761^{* *}$ & $7.270^{* *}$ & $7.333^{\star *}$ & $7.515^{\star *}$ \\
\hline & [9.98] & {$[8.74]$} & [10.35] & [43.37] & [31.76] & [41.30] \\
\hline Observations & 4082 & 4031 & 3445 & 4214 & 4160 & 3546 \\
\hline R-squared & 0.1026 & 0.1003 & 0.1017 & 0.0209 & 0.0188 & 0.0173 \\
\hline No of countries & 3 & 3 & 3 & 3 & 3 & 3 \\
\hline
\end{tabular}

Notes: Weighted OLS regressions for $44^{\prime} 000$ persons from 30 OECD countries. Dependent variable: Life satisfaction measured on a

10-point scale. Standard errors corrected for within-country correlation. '**', ‘’', '+' denote significances at the 1, 5 and 10 percent

levels, respectively. 'Other micro controls' include age, age squared, gender, education, occupational status, marital status, social capital, and attitudes. See Table A2 of the Appendix. 
Table A7: Perceived social mobility and income inequality: wage mobility subsample

\begin{tabular}{|c|c|c|c|c|c|c|c|c|}
\hline & 1 & 2 & 3 & 4 & 5 & 6 & 7 & 8 \\
\hline \multirow[t]{2}{*}{ Perc. soc. mob. } & $0.222^{* *}$ & 0.083 & $0.188^{* *}$ & 0.152 & $0.224^{* *}$ & 0.183 & $0.202^{* *}$ & 0.356 \\
\hline & {$[5.14]$} & {$[0.60]$} & {$[4.04]$} & {$[0.32]$} & {$[5.40]$} & [1.62] & {$[5.04]$} & [1.11] \\
\hline \multirow[t]{2}{*}{ Market Gini 2000} & -0.023 & -0.026 & & & & & & \\
\hline & {$[1.50]$} & {$[1.68]$} & & & & & & \\
\hline \multirow[t]{2}{*}{ Market Gini 2005} & & & & & -0.027 & -0.028 & & \\
\hline & & & & & {$[1.60]$} & {$[1.74]$} & & \\
\hline \multirow[t]{2}{*}{$\begin{array}{l}\text { Perc. soc. mob. } \\
\text { market Gini 2000/2005 }\end{array}$} & & 0.005 & & & & 0.001 & & \\
\hline & & [1.17] & & & & {$[0.41]$} & & \\
\hline \multirow[t]{2}{*}{ Final Gini 2000} & & & -0.039 & -0.040 & & & & \\
\hline & & & {$[1.84]$} & {$[1.53]$} & & & & \\
\hline \multirow[t]{2}{*}{ Final Gini 2005} & & & & & & & $-0.022+$ & -0.019 \\
\hline & & & & & & & [1.94] & {$[1.32]$} \\
\hline \multirow[t]{2}{*}{$\begin{array}{l}\text { Perc. soc. mob.* } \\
\text { final Gini } 2000 / 2005\end{array}$} & & & & 0.001 & & & & -0.003 \\
\hline & & & & {$[0.08]$} & & & & {$[0.47]$} \\
\hline Other micro controls & yes & yes & yes & yes & yes & yes & yes & yes \\
\hline \multirow[t]{2}{*}{$\log (\mathrm{NNI})$} & $-0.902^{*}$ & $-0.902^{*}$ & $-1.341^{*}$ & $-1.342^{*}$ & $-0.783^{*}$ & $-0.783^{*}$ & $-1.069^{* *}$ & $-1.064^{\star *}$ \\
\hline & {$[2.42]$} & {$[2.43]$} & {$[2.58]$} & {$[2.58]$} & {$[2.49]$} & {$[2.49]$} & [3.99] & [3.89] \\
\hline \multirow[t]{2}{*}{ Constant } & $16.713^{* *}$ & $16.806^{* *}$ & $22.396^{\star *}$ & $22.435^{\star \star}$ & $15.610^{* *}$ & $15.642^{* *}$ & $18.777^{\star *}$ & $18.621^{* *}$ \\
\hline & [3.92] & [3.99] & [3.57] & [3.53] & [4.35] & [4.42] & [5.97] & {$[5.74]$} \\
\hline Observations & 13049 & 13049 & 11985 & 11985 & 13049 & 13049 & 11985 & 11985 \\
\hline No of countries & 10 & 10 & 9 & 9 & 10 & 10 & 9 & 9 \\
\hline R-squared & 0.1114 & 0.1114 & 0.1171 & 0.1171 & 0.1115 & 0.1115 & 0.1152 & 0.1152 \\
\hline $\begin{array}{l}\text { F-test (Gini, soc. mob. } \\
\text { Perceptions) }\end{array}$ & 17.031 & & 17.0172 & & 16.532 & & 14.8765 & \\
\hline$p$-value & 0.0009 & & 0.0013 & & 0.001 & & 0.002 & \\
\hline $\begin{array}{l}\text { F-test (soc. mob. perc., } \\
\text { soc.mob. perc. * Gini) }\end{array}$ & & 20.763 & & 8.1332 & & 15.3439 & & 13.7424 \\
\hline$p$-value & & 0.0004 & & 0.0118 & & 0.0013 & & 0.0026 \\
\hline
\end{tabular}

Notes: Weighted OLS regressions for 44'000 persons from 30 OECD countries. Dependent variable: Life satisfaction measured on a 10-point scale. Standard errors corrected for within-country correlation. '**', '*', ' + ' denote significances at the 1,5 and 10 percent levels, respectively. 'Other micro controls' include age, age squared, gender, education, occupational status, marital status, social capital, and attitudes. See Table A2 of the Appendix. 
Table A8: Correlations between income inequality and social mobility perceptions

\begin{tabular}{|l|c|c|c|c|}
\hline & Perc.soc. mob. & Perc.soc. mob. 2 & Laziness & Escape poverty \\
\hline & & & & \\
\hline Market Gini 2000 & -0.1251 & -0.1329 & 0.1342 & -0.1596 \\
\hline Market Gini 2005 & -0.0949 & -0.121 & 0.1002 & -0.1264 \\
\hline Final Gini 2000 & -0.1606 & -0.1239 & 0.1362 & -0.1584 \\
\hline Final Gini 2005 & -0.1185 & -0.1329 & 0.1342 & -0.1596 \\
\hline
\end{tabular}

Table A9: Correlations between income inequality and actual social mobility

\begin{tabular}{|l|c|c|c|}
\hline & $\begin{array}{c}\text { Intergenerational } \\
\text { mobility in labour } \\
\text { market }\end{array}$ & $\begin{array}{c}\text { Intergenerational } \\
\text { Mobility in } \\
\text { educational } \\
\text { attainment } \\
\text { (mother) }\end{array}$ & $\begin{array}{c}\text { Intergenerational } \\
\text { Mobility in } \\
\text { educational } \\
\text { attainment (father) }\end{array}$ \\
\hline Market Gini 2000 & -0.5875 & 0.4532 & 0.3907 \\
\hline Market Gini 2005 & -0.6205 & 0.1739 & 0.026 \\
\hline Final Gini 2000 & -0.6884 & -0.0066 & 0.08 \\
\hline Final Gini 2005 & 0.6707 & -0.1181 & 0.0204 \\
\hline
\end{tabular}




\section{OECD SOCIAL, EMPLOYMENT AND MIGRATION WORKING PAPERS}

Most recent releases are:

No. 94 THE LABOUR MARKET INTEGRATION OF IMMIGRANTS AND THEIR CHILDREN IN NORWAY Thomas Liebig (2009)

No. 92 HOW EXPENSIVE IS THE WELFARE STATE? GROSS AND NET INDICATORS IN THE OECD SOCIAL EXPENDITURE DATABASE (SOCX)

Willem Adema and Maxime Ladaique (forthcoming)

No. 91 SHOULD PENSION SYSTEMS RECOGNISE “HAZARDOUS AND ARDUOUS WORK”? Asghar Zaidi and Edward Whitehouse (2009)

No. 90 GOING SEPARATE WAYS? SCHOOL-TO-WORK TRANSITIONS IN THE UNITED STATES AND EUROPE

Glenda Quintini and Thomas Manfredi (2009)

No. 89 LEGISLATION, COLLECTIVE BARGAINING AND ENFORCEMENT: UPDATING THE OECD EMPLOYMENT PROTECTION INDICATORS

Danielle Venn (2009)

No. 88 TOWARDS A FRAMEWORK FOR ASSESSING FAMILY POLICIES IN THE EU Henning Lohmann, Frauke H. Peter, Tine Rostgaard and C. Katharina Spiess (2009)

No. 87 INVESTMENT RISK: IMPACT ON RETIREMENT INCOMES AND GOVERNMENT BUDGETS Edward Whitehouse, Anna Cristina D'Addio and Andrew Reilly (2009)

No. 86 PENSION REFORM IN CHILE REVISITED: WHAT HAS BEEN LEARNED? Augusto Iglesias Palau (2009)

No. 85 INEQUALITY, POVERTY AND SOCIAL POLICY: RECENT TRENDS IN CHILE Osvaldo Larrañaga (2009)

No. 84 PENSION SCHEMES FOR THE SELF-EMPLOYED IN OECD COUNTRIES Jongkyun Choi (2009)

No. 83 WORK, JOBS AND WELL-BEING ACROSS THE MILLENNIUM Andrew Clark (2009)

No. 82 CHILD WELL-BEING AND SOLE PARENT FAMILY STRUCTURE IN THE OECD: AN ANALYSIS Simon Chapple (2009)

No. 81 A GOOD TIME FOR MAKING WORK PAY? TAKING STOCK OF IN-WORK BENEFITS AND RELATED MEASURES ACROSS THE OECD

Herwig Immervoll and Mark Pearson (2009)

No. 80 MAIN FEATURES OF THE PUBLIC EMPLOYMENT SERVICE IN POLAND Daniela Kalužná (2009)

No. 79 MANAGING HIGHLY-SKILLED LABOUR MIGRATION: A COMPARATIVE ANALYSIS OF MIGRATION POLICIES AND CHALLENGES IN OECD COUNTRIES

Jonathan Chaloff and Georges Lemaitre (2009)

No. 78 ACTIVATION POLICIES IN NORWAY

Nicola Duell, Shruti Singh and Peter Tergeist (2009)

No. 77 PENSION, PURCHASING-POWER RISK, INFLATION AND INDEXATION Edward Whitehouse (2009)

No. 76 AN EVALUATION OF THE TAX-TRANSFER TREATMENT OF MARRIED COUPLES IN EUROPEAN COUNTRIES

Herwig Immervoll, Henrik Jacobsen Kleven, Claus Thustrup Kreiner and Nicolaj Verdelin (2009)

Other series of working papers available from the OECD include: OECD HEALTH WORKING PAPERS. 


\section{RECENT RELATED OECD PUBLICATIONS:}

INTERNATIONAL MIGRATION OUTLOOK (2009)

PENSIONS AT A GLANCE 2009: Retirement-Income Systems in OECD Countries (2009)

JOBS FOR YOUTH: FRANCE (2009)

SOCIETY AT A GLANCE 2009 - OECD Social Indicators (2009)

JOBS FOR YOUTH: AUSTRALIA (2009)

OECD REVIEWS OF LABOUR MARKET AND SOCIAL POLICIES: CHILE (2009)

PENSIONS AT A GLANCE - SPECIAL EDITION: ASIA/PACIFIC (2009)

GROWING UNEQUAL? Income Distribution and Poverty in OECD Countries (2008)

SICKNESS, DISABILITY AND WORK: BREAKING THE BARRIERS (VOL. 3) - DENMARK, FINLAND, IRELAND AND THE NETHERLANDS (2008)

JOBS FOR YOUTH: JAPAN (2008)

JOBS FOR YOUTH: CANADA (2008)

JOBS FOR YOUTH: NETHERLANDS (2008)

JOBS FOR YOUTH: NEW ZEALAND (2008)

JOBS FOR YOUTH: NORWAY (2008)

JOBS FOR YOUTH: UNITED KINGDOM (2008)

A PROFILE OF IMMIGRANT POPULATIONS IN THE $21^{\text {ST }}$ CENTURY (2008)

OECD EMPLOYMENT OUTLOOK (2008)

OECD LABOUR FORCE STATISTICS: 1987-2007 (2008)

INTERNATIONAL MIGRATION OUTLOOK - 2008 Edition

IMMIGRATION HEALTH WORKERS IN OECD COUNTRIES IN THE BROADER CONTEXT OF HIGHLY SKILLED MIGRATION (2008)

OECD REVIEWS OF LABOUR MARKET AND SOCIAL POLICIES IN SERBIA (2008)

JOBS FOR IMMIGRANTS (VOL. 2): Labour Market Integration in Belgium, France, The Netherlands and Portugal (2008)

MODERNISING SOCIAL POLICY FOR THE NEW LIFE COURSE (2007)

BABIES AND BOSSES - Reconciling Work and Family Life: A Synthesis of Findings for OECD Countries (2007)

BENEFITS AND WAGES - OECD Indicators (2007)

FACING THE FUTURE: KOREA'S FAMILY, PENSION AND HEALTH POLICY CHALLENGES (2007)

PENSIONS AT A GLANCE: Public Policies across OECD Countries (2007)

For a full list, consult the OECD On-Line Bookstore at www.oecd.org. 